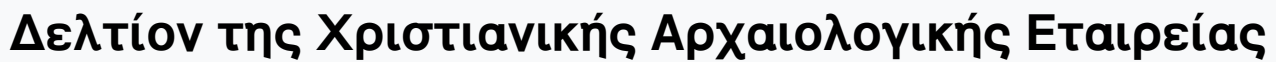

Tó 16 (1992)

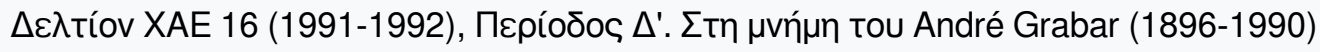

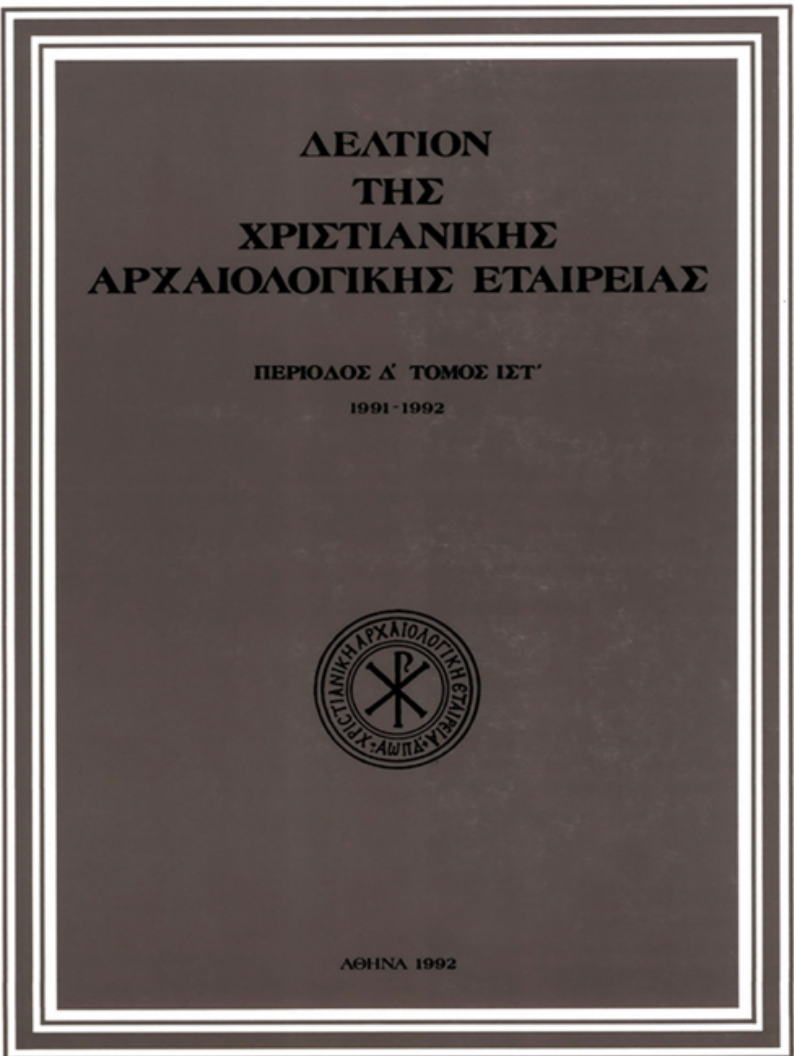

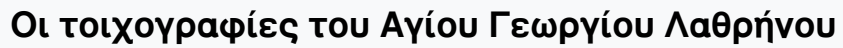

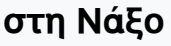

\section{Mapía ПANATISTIDH}

doi: $\underline{10.12681 / \text { dchae. } 1063}$

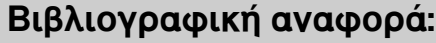

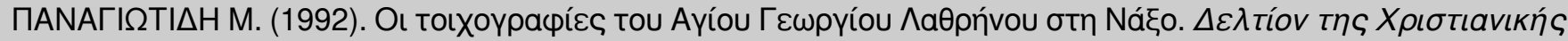

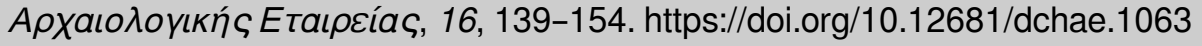




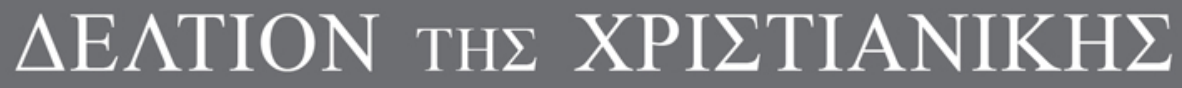 APXAIO $\Lambda$ OГIKH $\Sigma$ ETAIPEIA $\Sigma$}

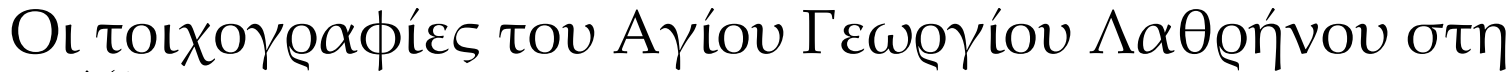
Nóko

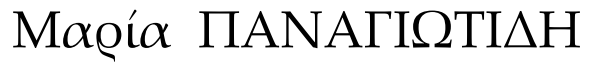

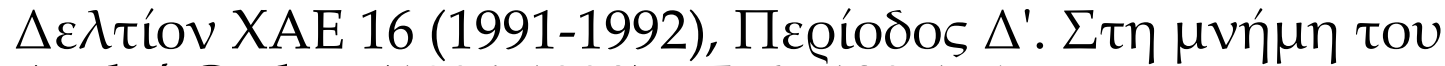
André Grabar (1896-1990)• $\Sigma \varepsilon \lambda$. 139-154

A@HNA 1992 


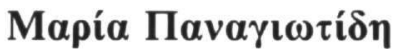

\section{OI TOIXОГРАФIE $\Sigma$ TOY АГIOY ГЕ}

'E

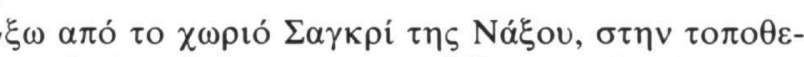

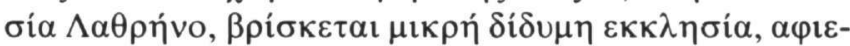

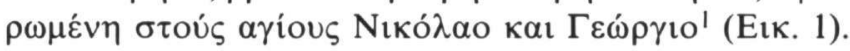

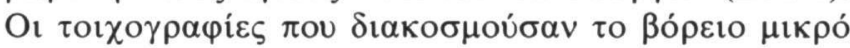

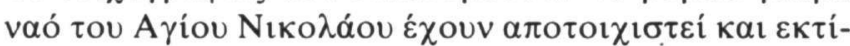

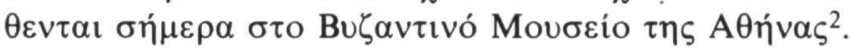

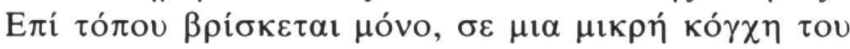

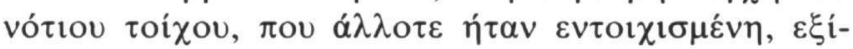

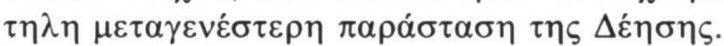

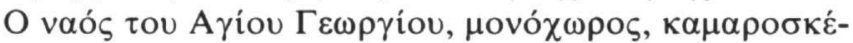

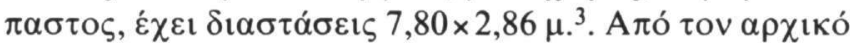

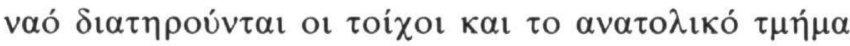

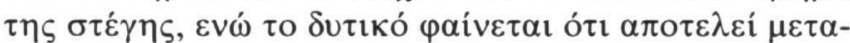

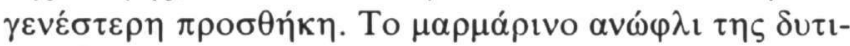

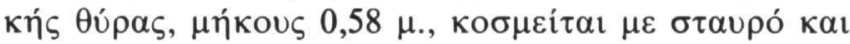

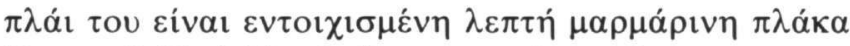

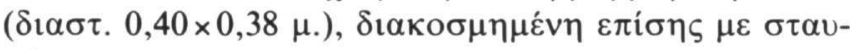
pó.

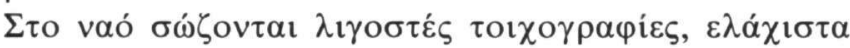

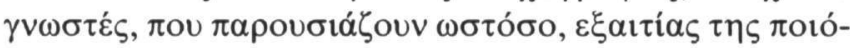

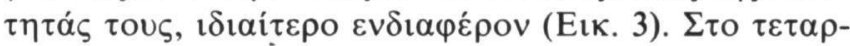

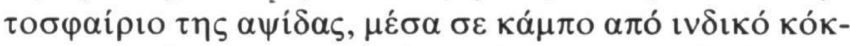

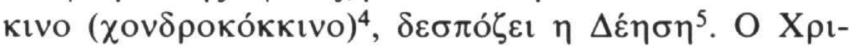

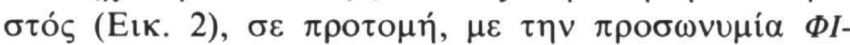

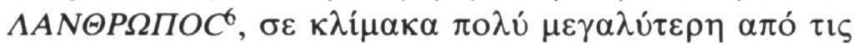

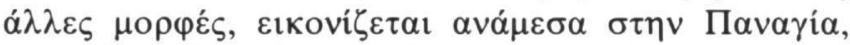

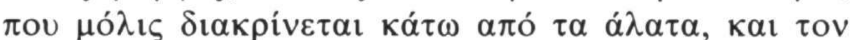

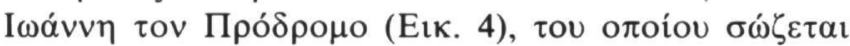

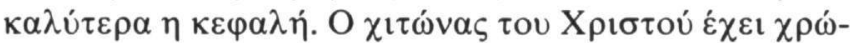

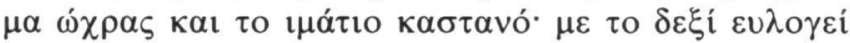

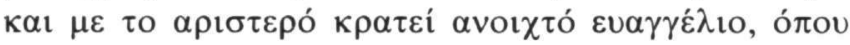

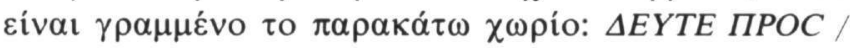

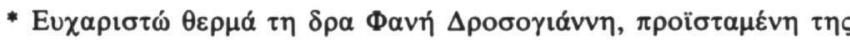
$2 \eta \varsigma$ Е

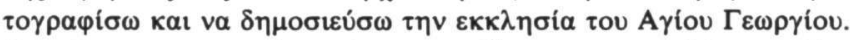

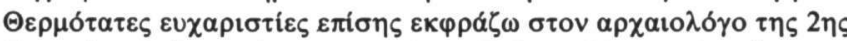
Е

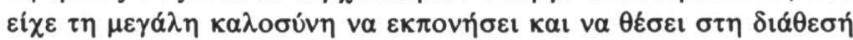

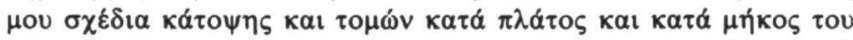

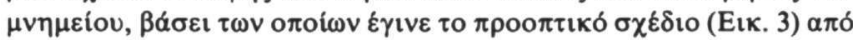

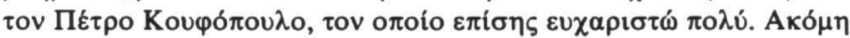

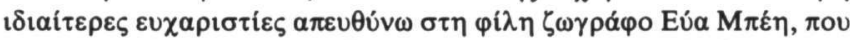

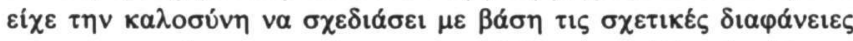

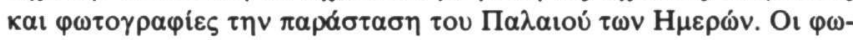

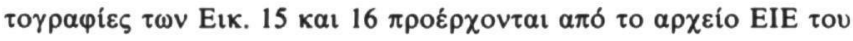

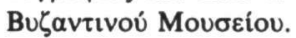

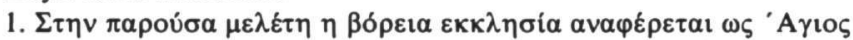

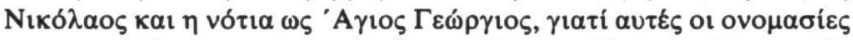

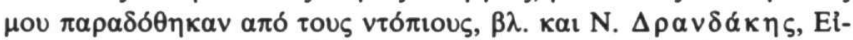

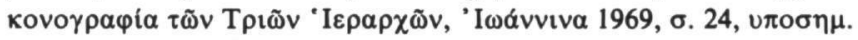

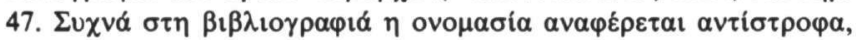

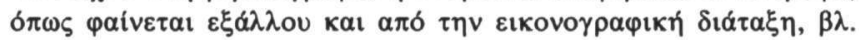
$\pi \alpha \rho \alpha \kappa \alpha ́ \tau \omega$, Eıк. 3.

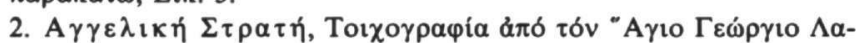

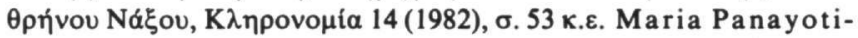
di, Les peintures murales de Naxos, CorsiRav 38 (1991), $\sigma .295$, દıк.

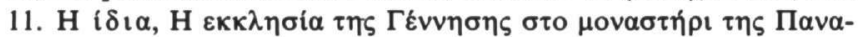

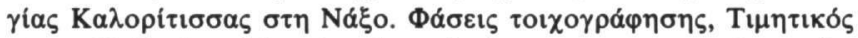

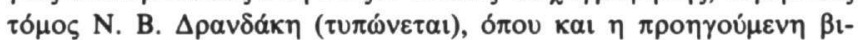

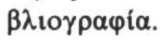

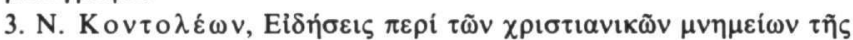

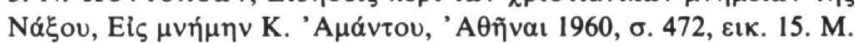

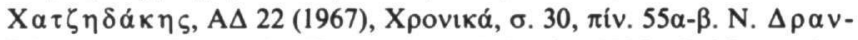

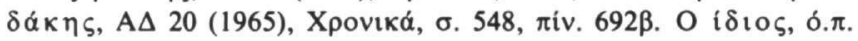

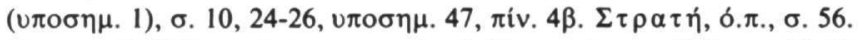

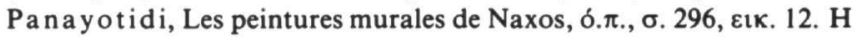

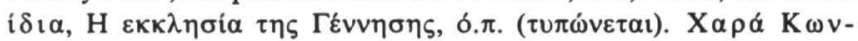

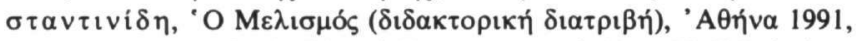

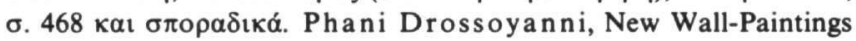
from the Cyclades, XVIIIe Congrès International des études byzantines, Moscou 1991, Résumés des Communications I, $\boldsymbol{\sigma} .290$.

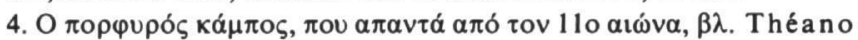
Chatzidakis-Bacharas, Les peintures murales de Hosios Loukas.

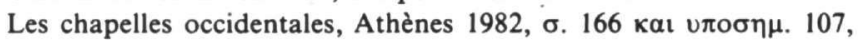

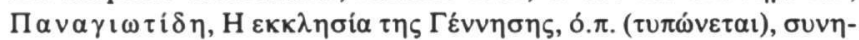

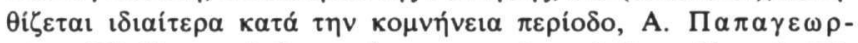

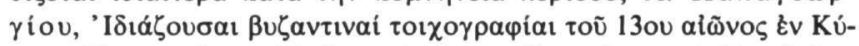

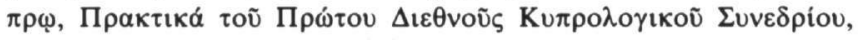
$\Lambda \varepsilon \cup \kappa \omega \sigma i \alpha 1969$ (1972), б. 209-210.

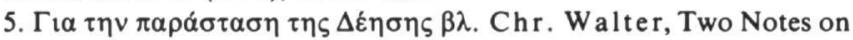
the Deesis, REB $26(1968), \sigma .311$ K.e., o i $\delta 10$, Further Notes on the

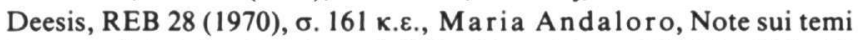
iconografici della Deesis e dell'Haghiosoritissa, RIASA, N.S. 17

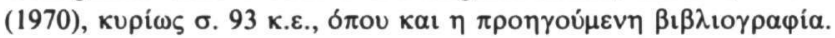

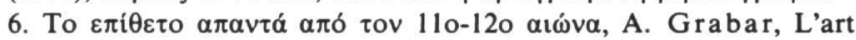
religieus et l'empire byzantin à l'époque des Macédoniens, L'art de la

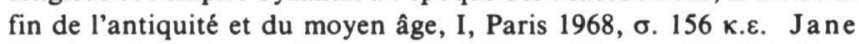
Timken-Matthews, Pantocrator: Title and Image (Ph. D.), New

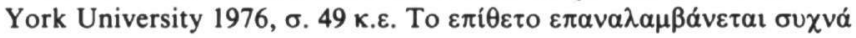

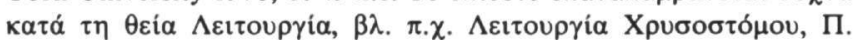

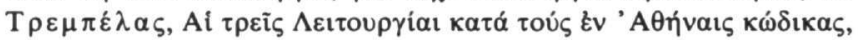
'A

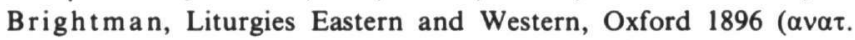
1965), б. 359.5, 20, 360.36, 366.25, 371.25, 374.4, 376.16, 390.18, 26, 395.33 . 


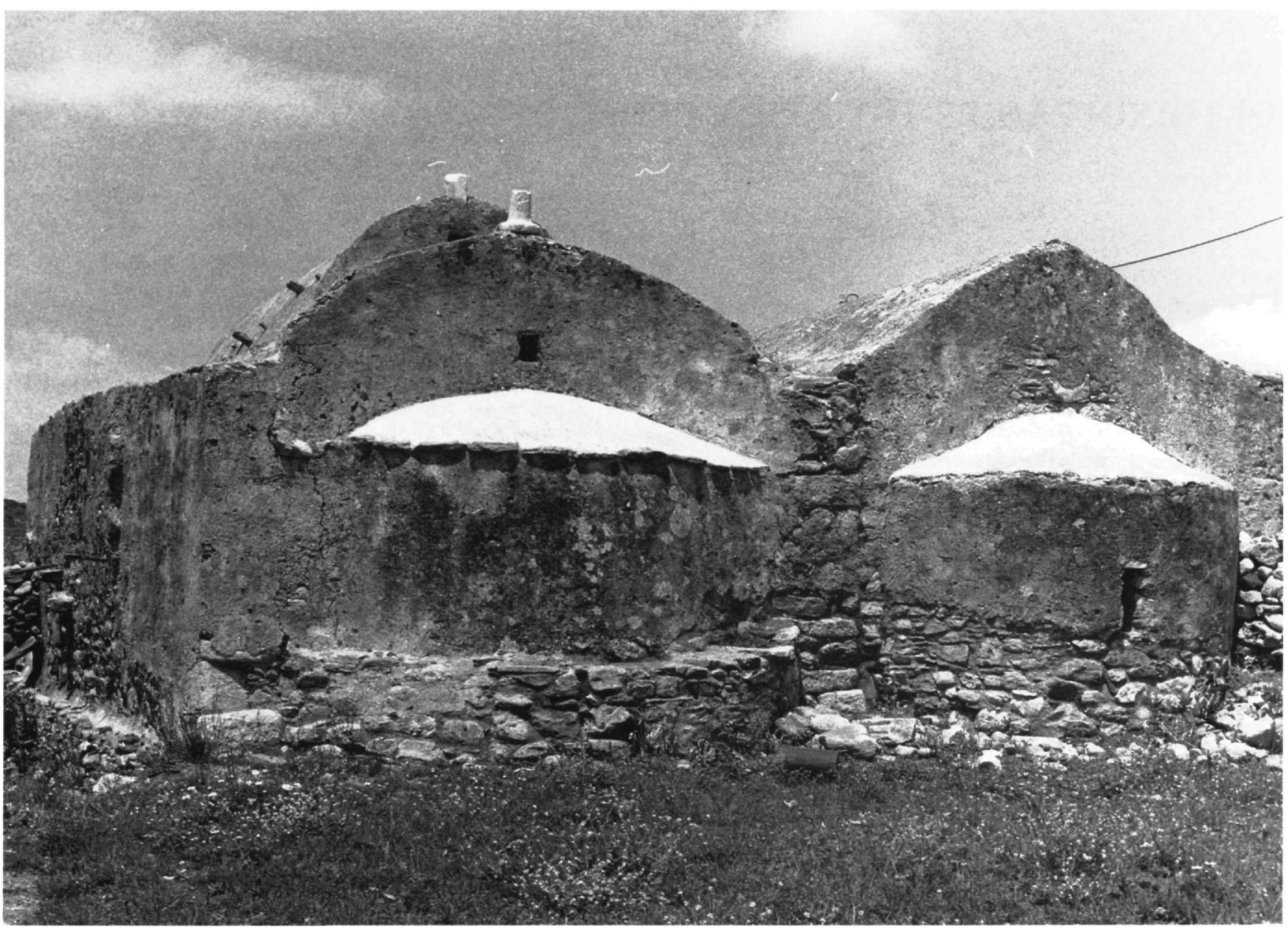

ME ПАNTEC / OI KOПION/TEC KAI ПE/ФOPTICME/-

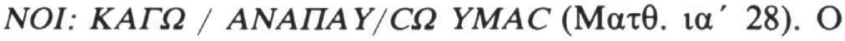

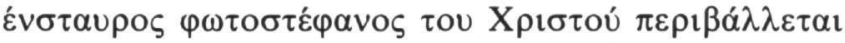

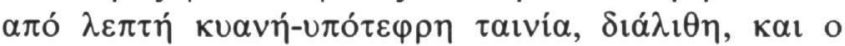

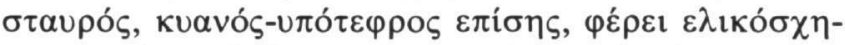

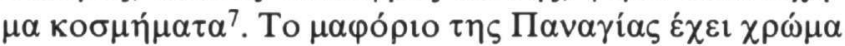

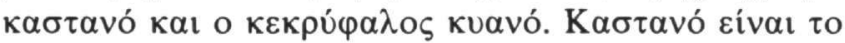

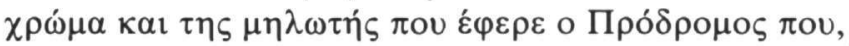

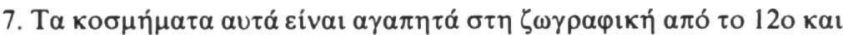

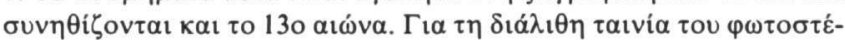

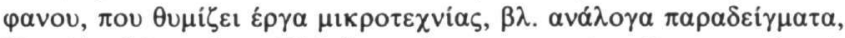

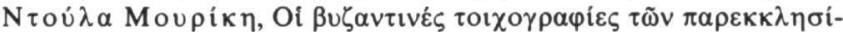

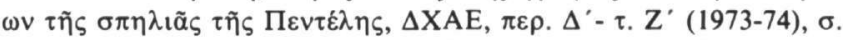

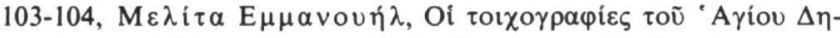

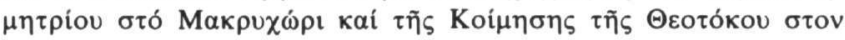

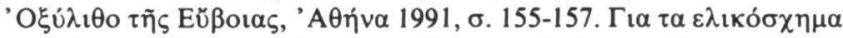
$\kappa о \sigma \mu \eta \dot{\mu} \mu \alpha \alpha, \beta \lambda$. Zagorka Janc, Ornamenti Fresaca, Beograd 1961,

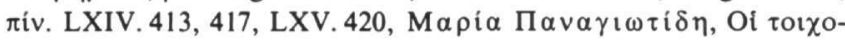

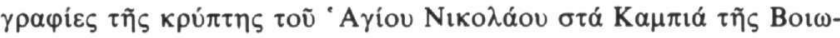
tías, Actes XVe Congrès International d'études byzantines, Athènes

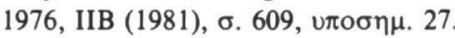

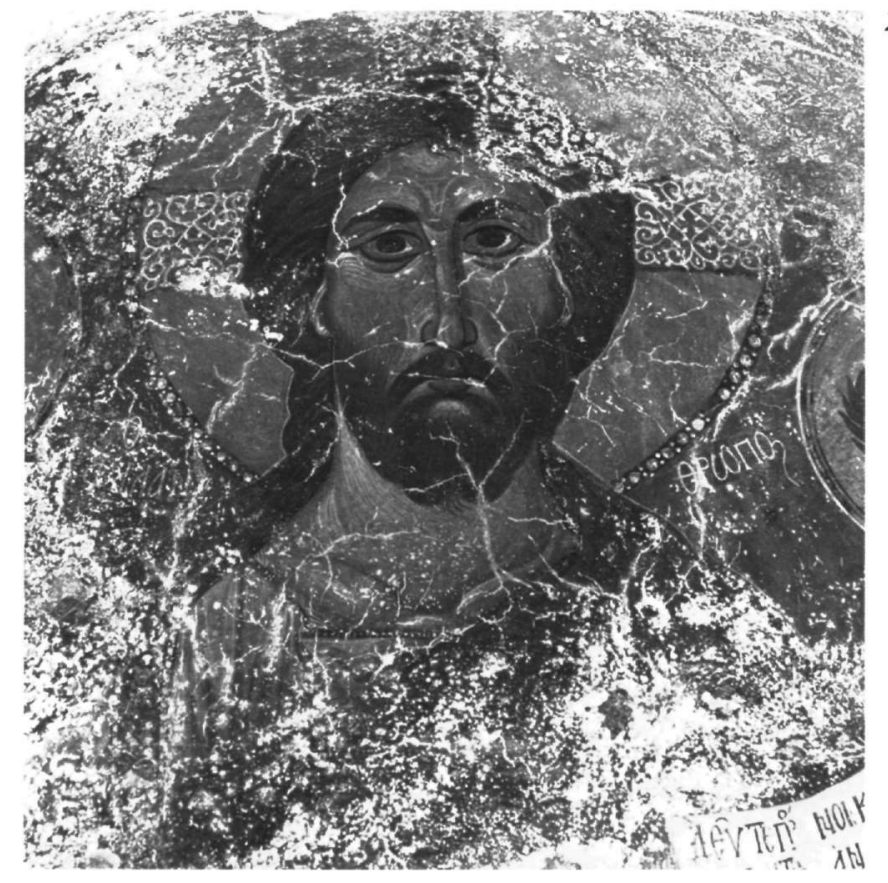




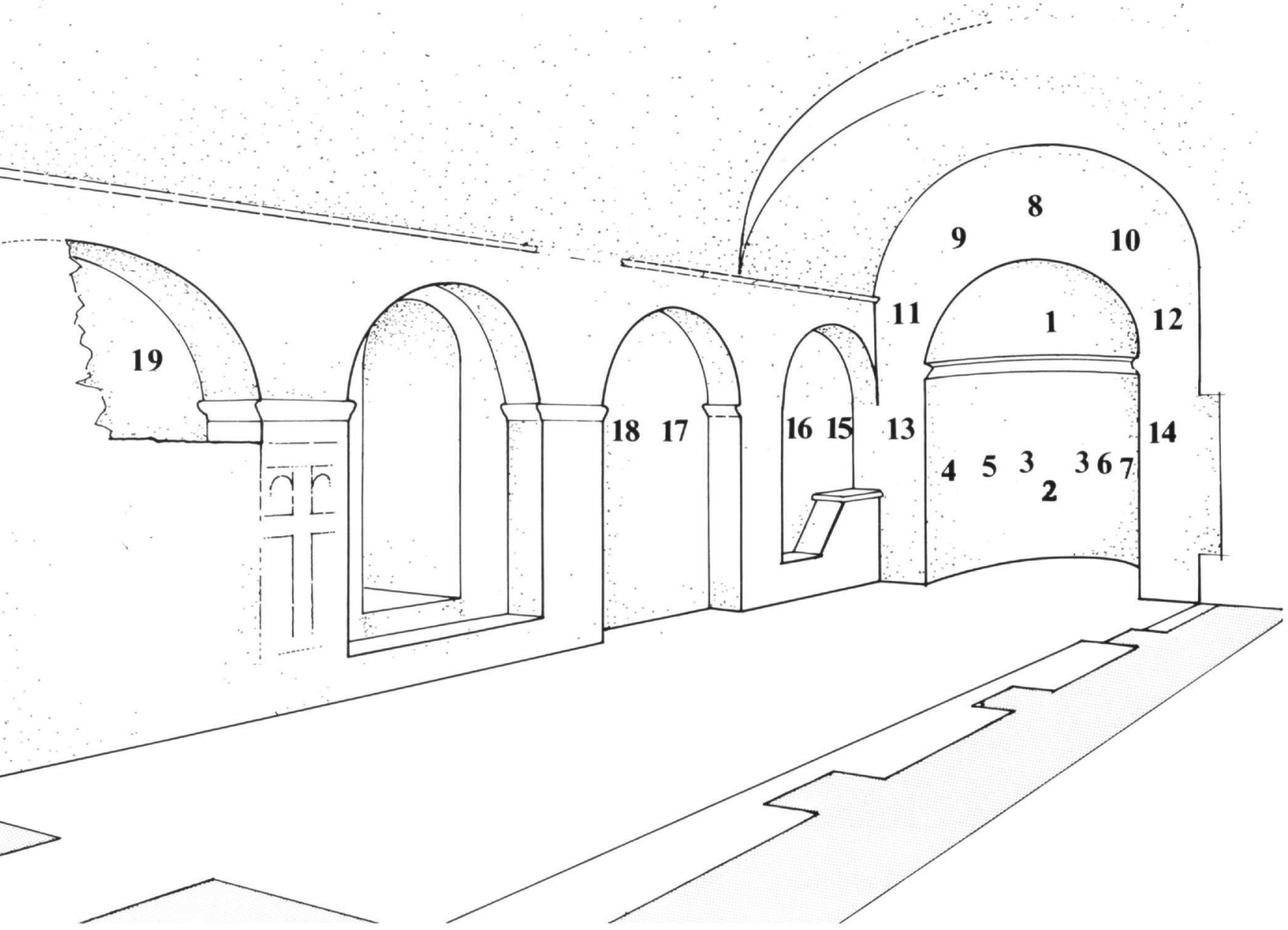

4

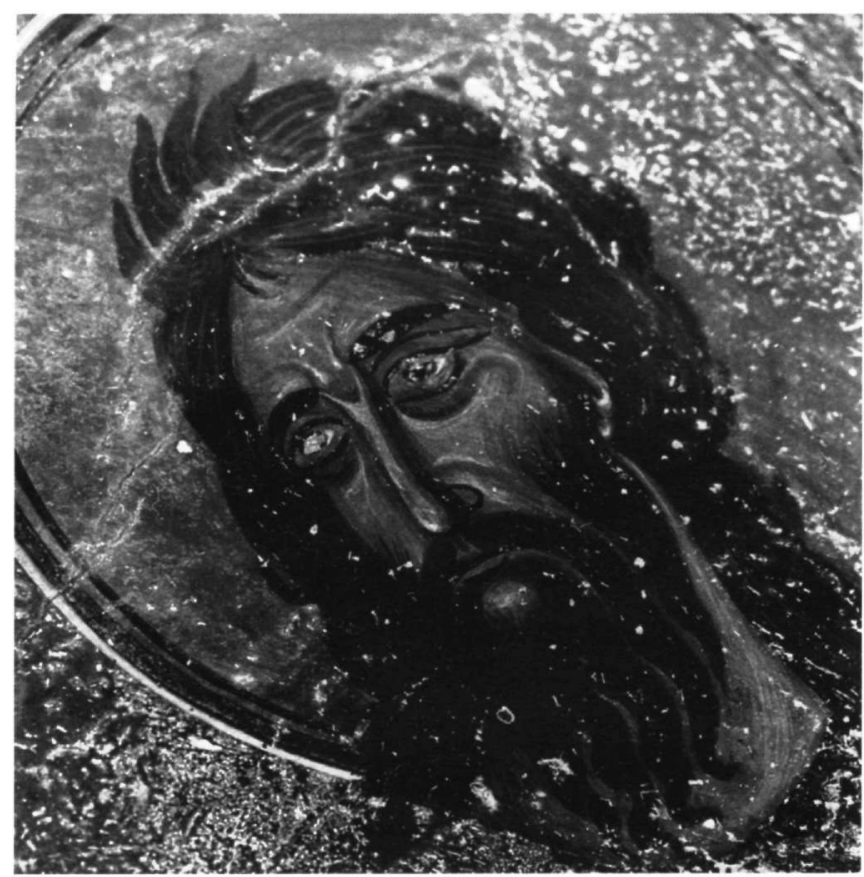

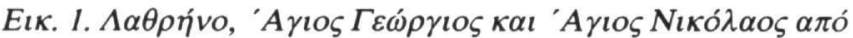
$\alpha v \alpha \tau o \lambda \iota \kappa \alpha ́$.

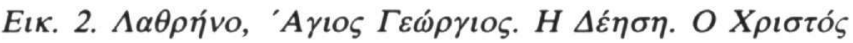
$(\lambda \varepsilon \pi \tau \sigma \mu \varepsilon \dot{\varepsilon} \rho \varepsilon \imath \alpha)$.

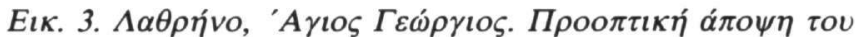
$\varepsilon \sigma \omega \tau \varepsilon \rho \iota \kappa о \dot{~ \chi \omega ́ \rho о \nu . ~}$
1. $\Delta \dot{\varepsilon} \eta \sigma \eta$
1. I

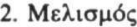
12. 'Avva
3. 'A
13. $\Delta$ tákovo $\Sigma \tau \dot{\varepsilon} \varphi \alpha v o \zeta$

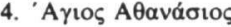

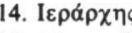

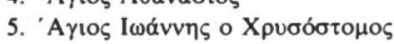
15. 'A
6. 'A
16. Aria

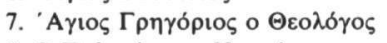

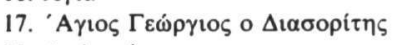

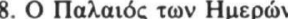
18. A $\pi \delta \sigma \tau 0 \lambda \circ$

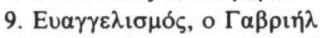

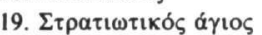

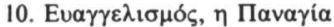

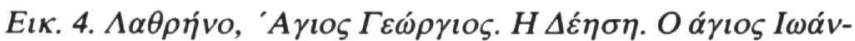

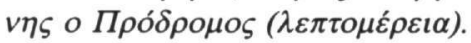




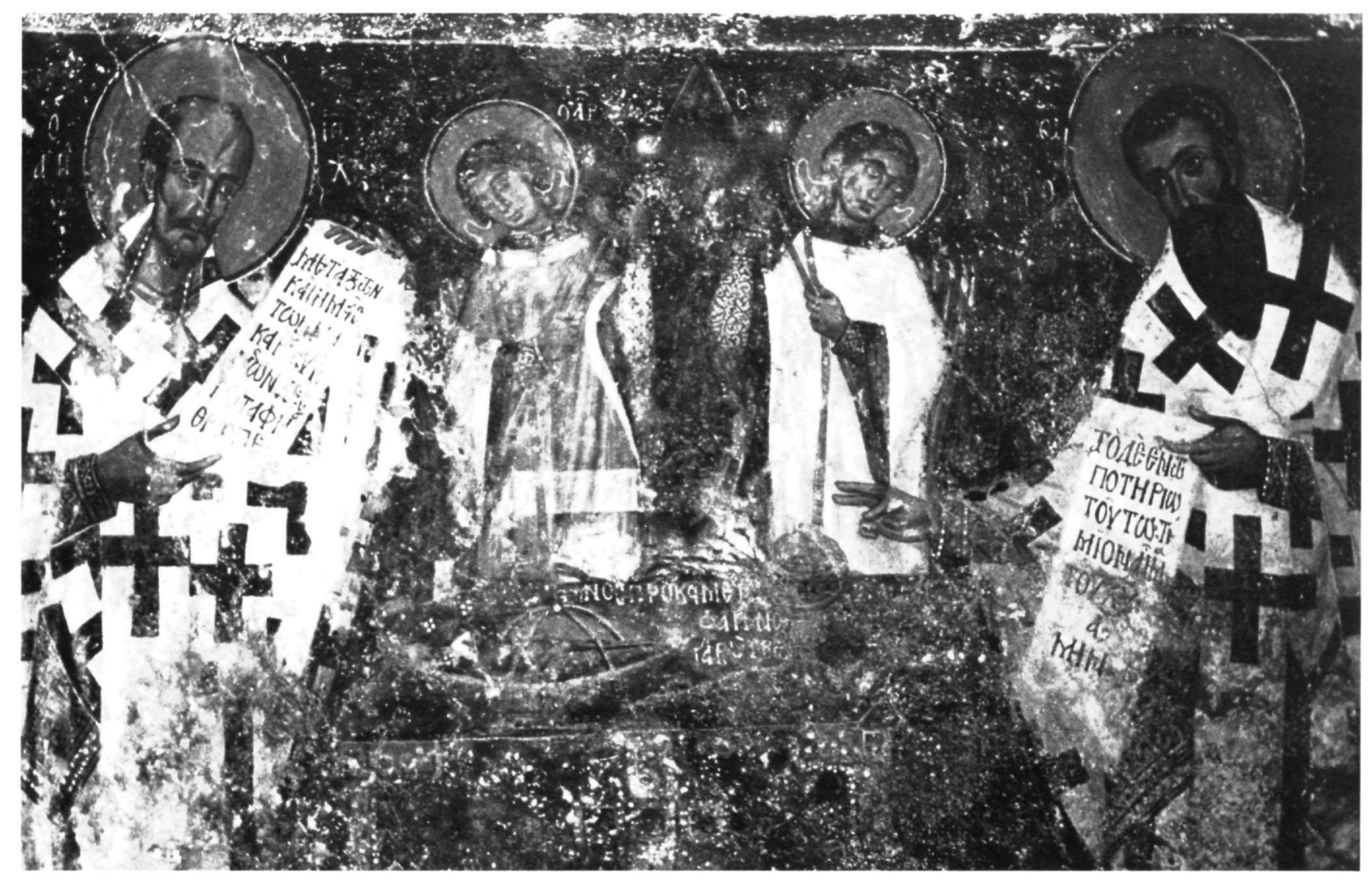

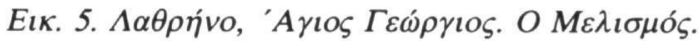

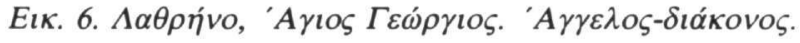

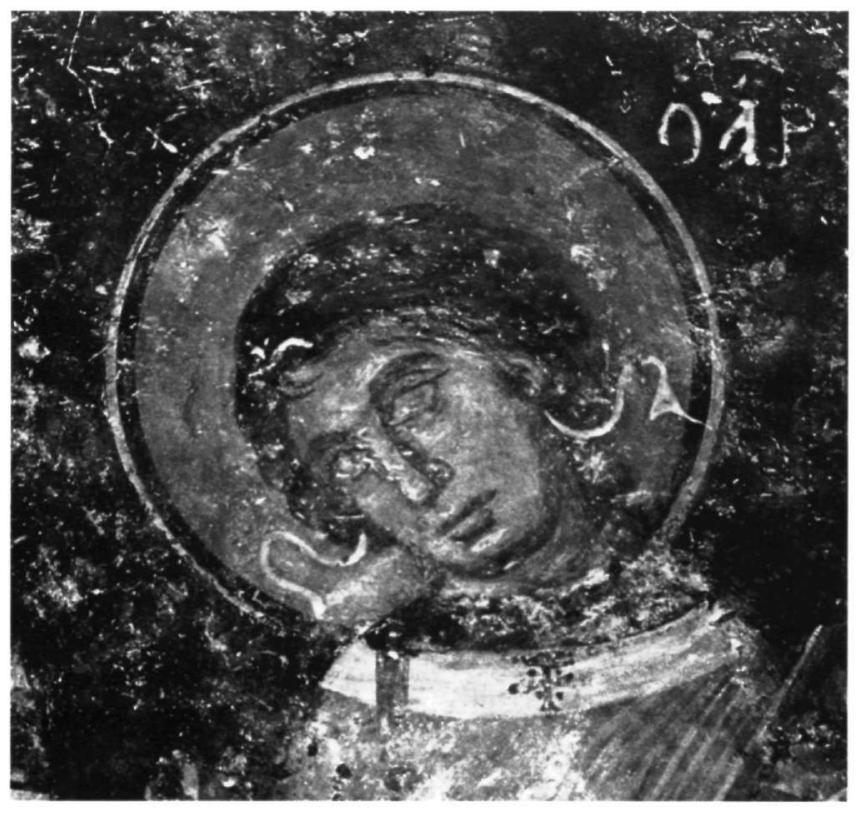

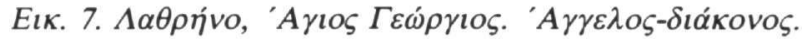

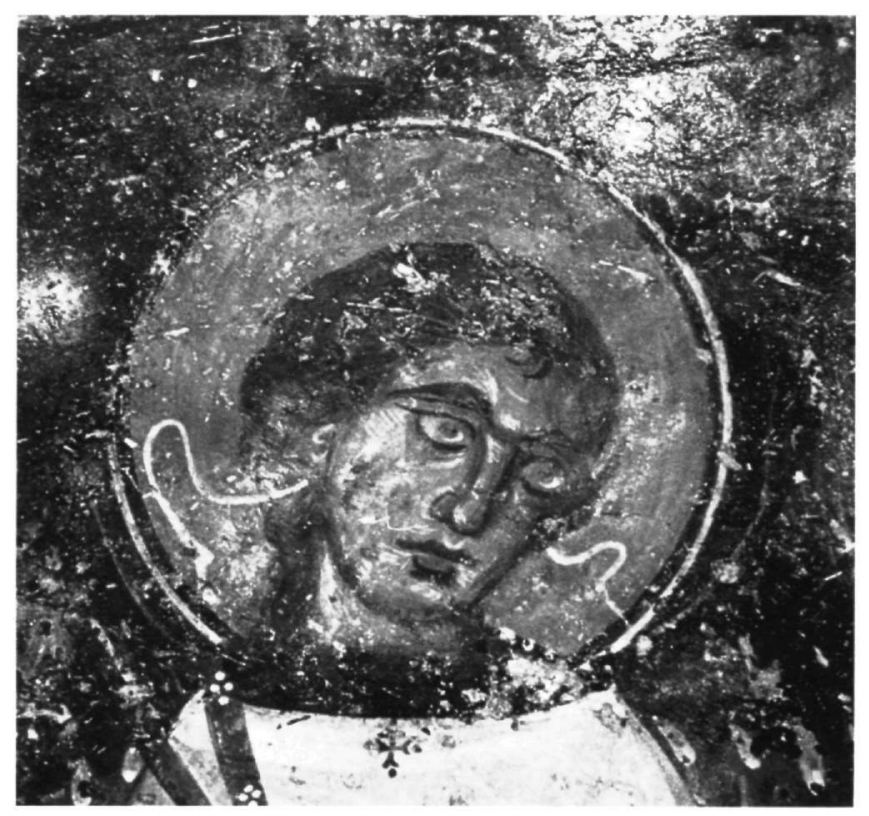




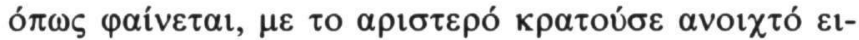

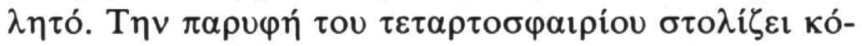

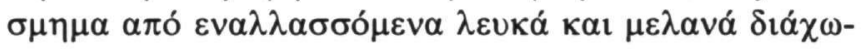

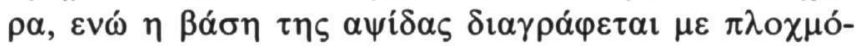

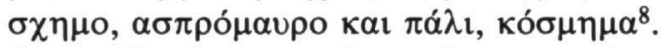

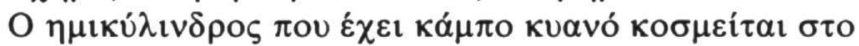

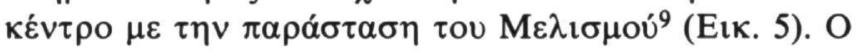

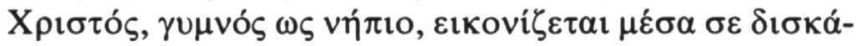

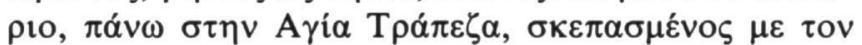

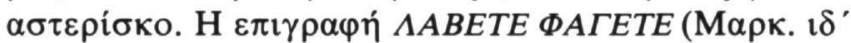

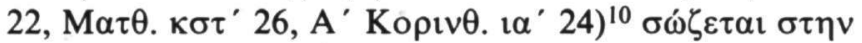

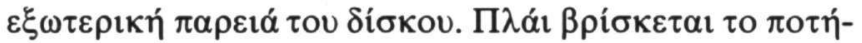

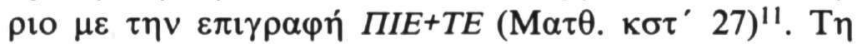

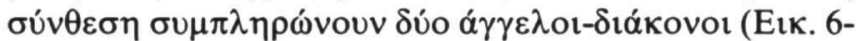

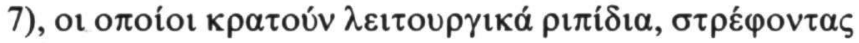

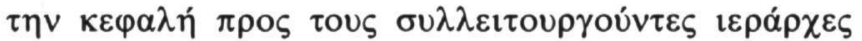

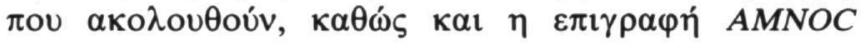
ПPOKEIME M[YCTIKS]C / [EC]ФAГM[E]NOC MEAI[-

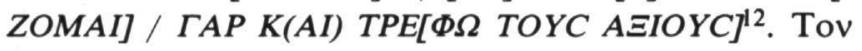

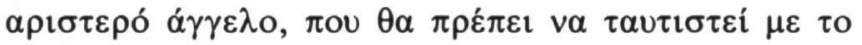

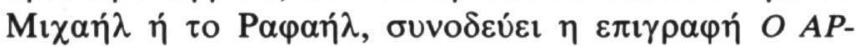

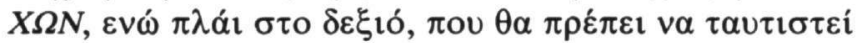

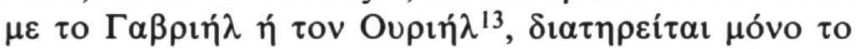

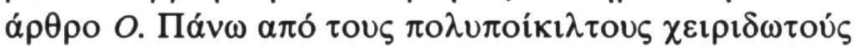

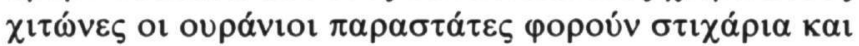

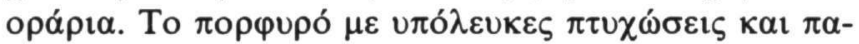

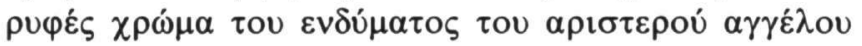

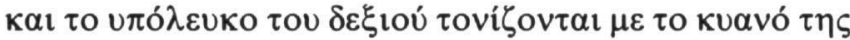

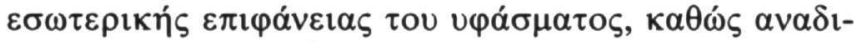

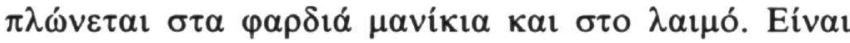

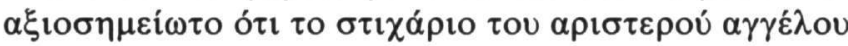

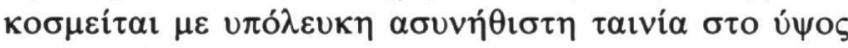
$\tau \omega v \mu \eta \rho \omega ́ v$.

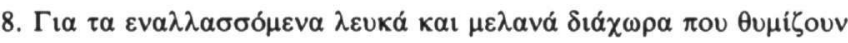

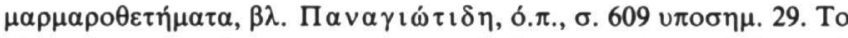

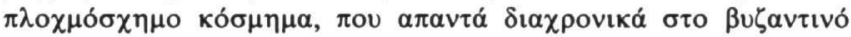

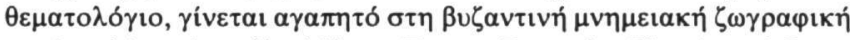

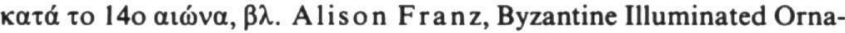

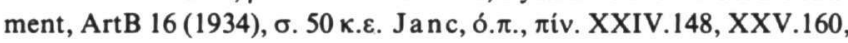
XXVI.161.

9. Gordana Babić, Les discussions christologiques et le décor des églises byzantines au XIIe siècle. Les évêques officiant devant l'Hétimasie et devant l'Amnos, Frühmittelalterliche Studien 2 (1968), б. 368

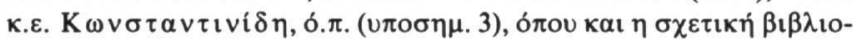
$\gamma \rho \alpha \varphi i \alpha$.

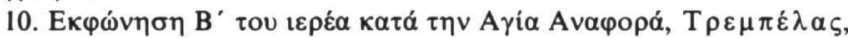

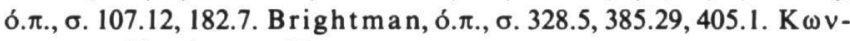
$\sigma \tau \alpha \vee \tau \imath v i \delta \eta, \delta . \pi ., \sigma .89$.

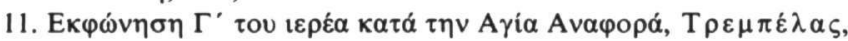

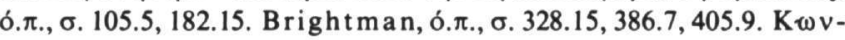
$\sigma \tau \alpha v \tau \imath v i \delta \eta, \delta . \pi ., \sigma .90$.

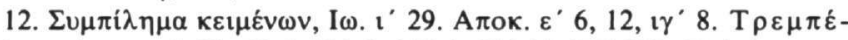

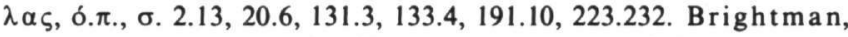

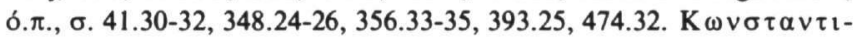

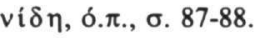

13. D. Pallas, Himmelsmächte. Erzengel und Engel, RbK III, $\sigma \tau$. 50

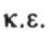

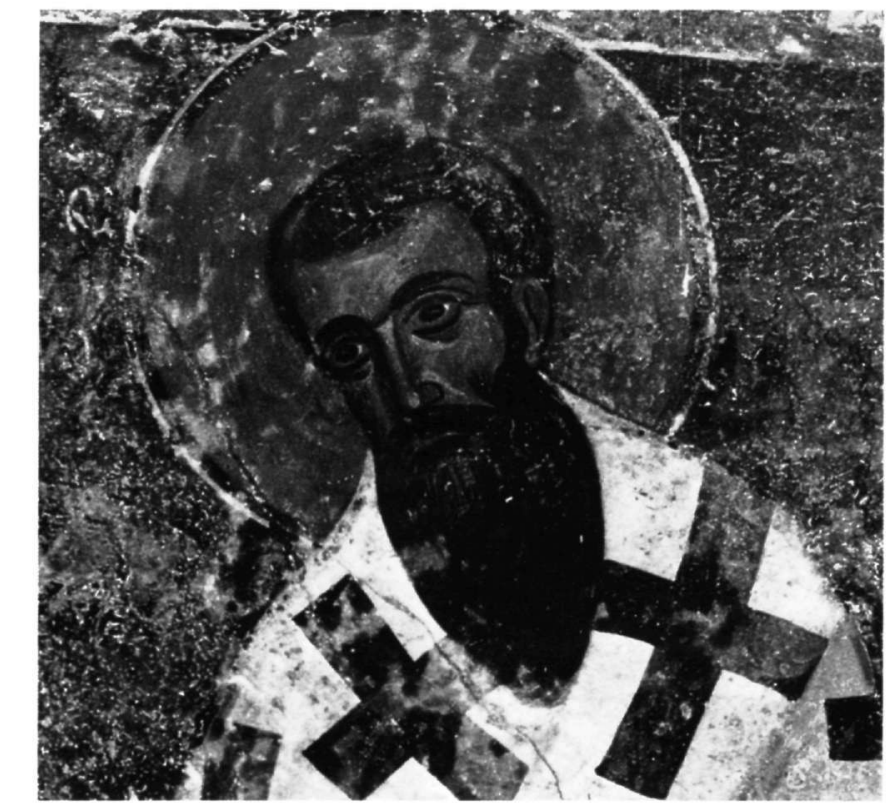

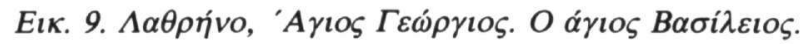

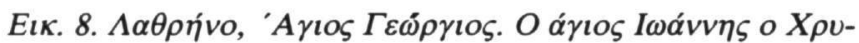

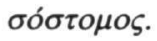

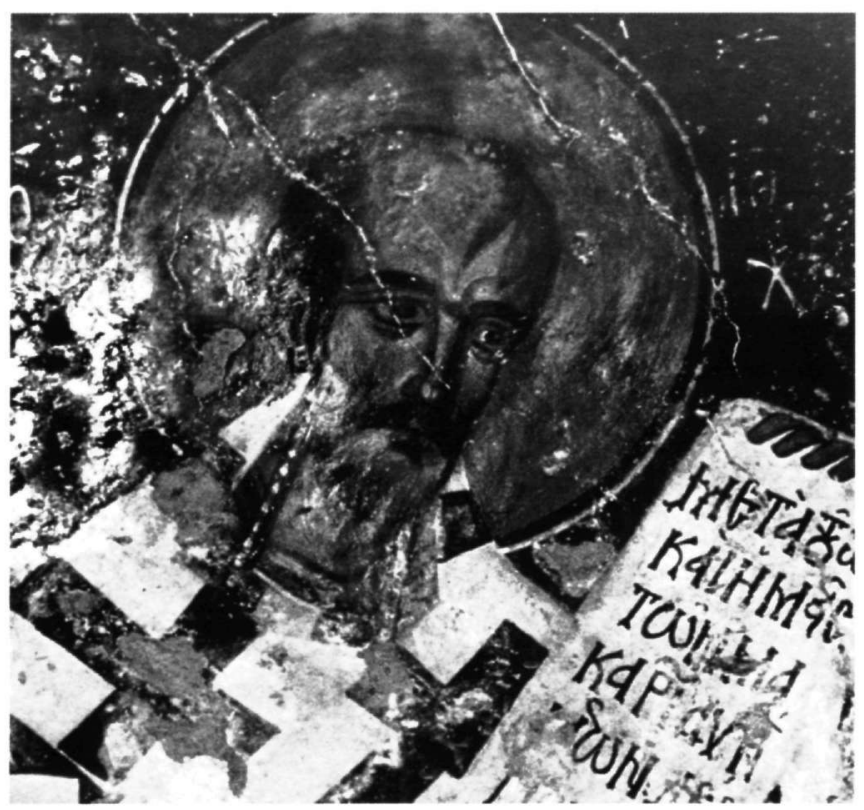




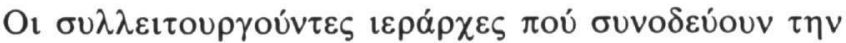

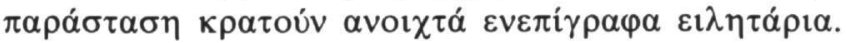

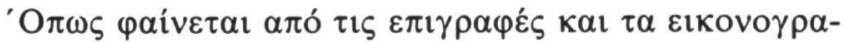

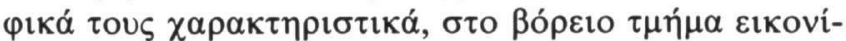

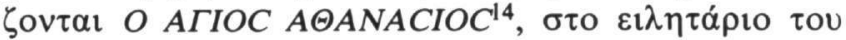

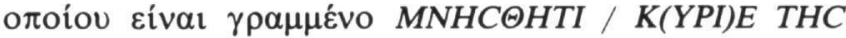
ПO/

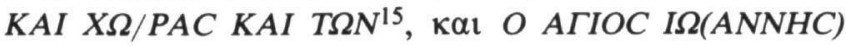

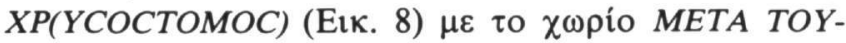
$T \Omega N$ / KAI HMEIC / TSN MA/KAPI(SN) $\triangle Y N A / M E \Omega N$ :

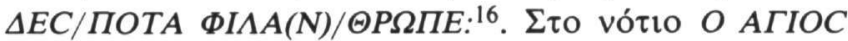

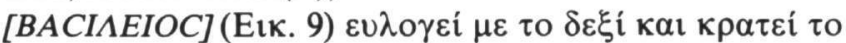

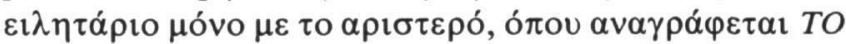

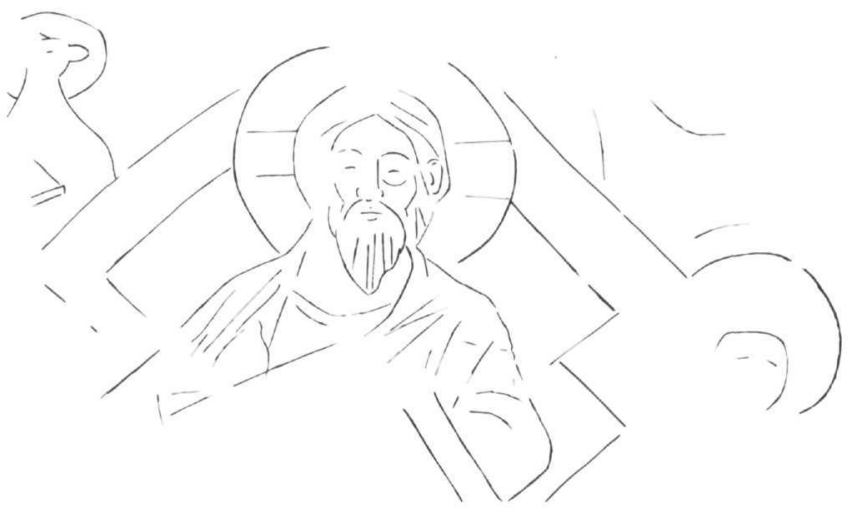

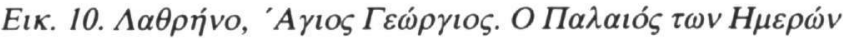
( $\sigma \chi \varepsilon \dot{\varepsilon} \delta i o)$.

$\triangle E$ EN TS / ПOTHPIS / TOYTS TI/MION AIMA / TOY

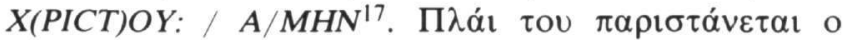

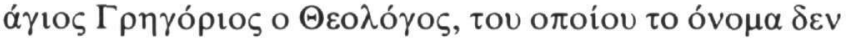

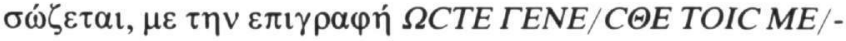

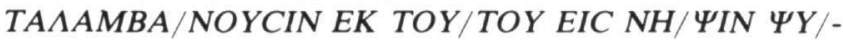

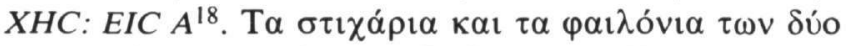

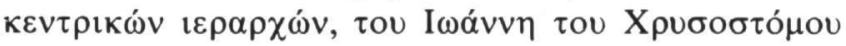

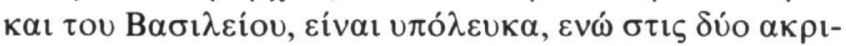

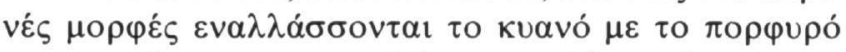

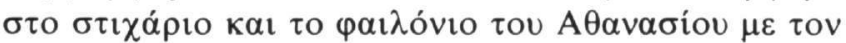

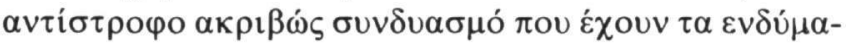

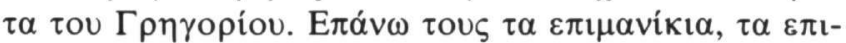

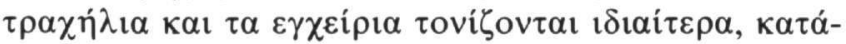

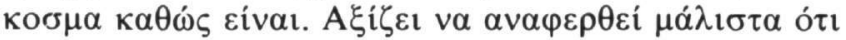

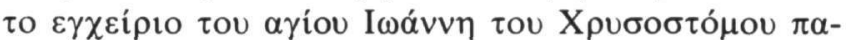

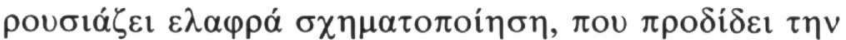

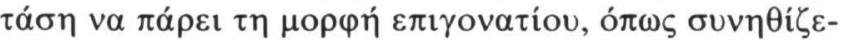

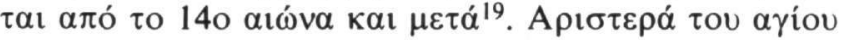

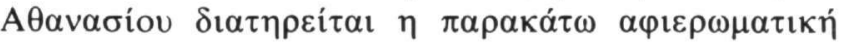

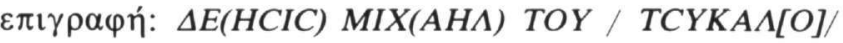
ПOYА[OY] $K(A I) / T(H C) C Y M / B H[O Y] E(T O Y C)$ $\varsigma^{\prime} \ldots[I] N[\triangle I K T I O N O C]$.

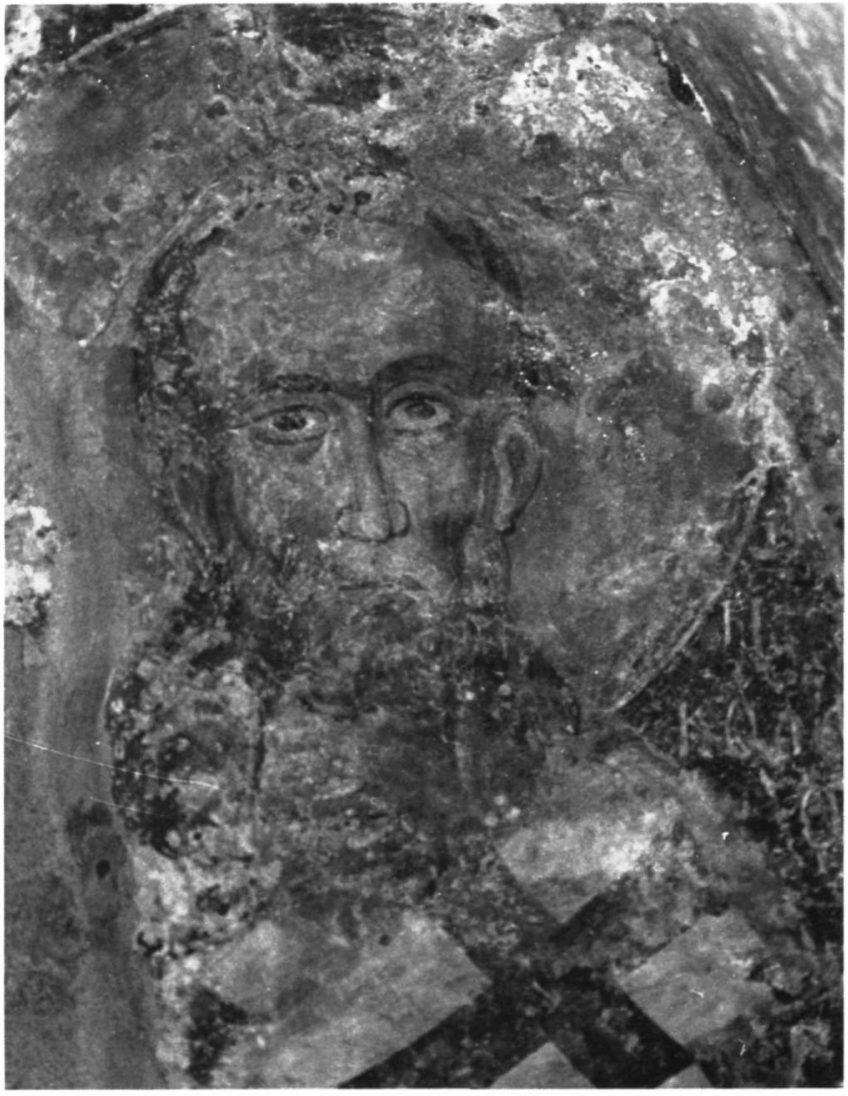

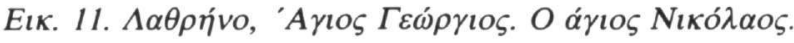

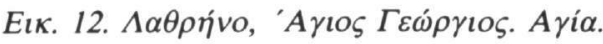

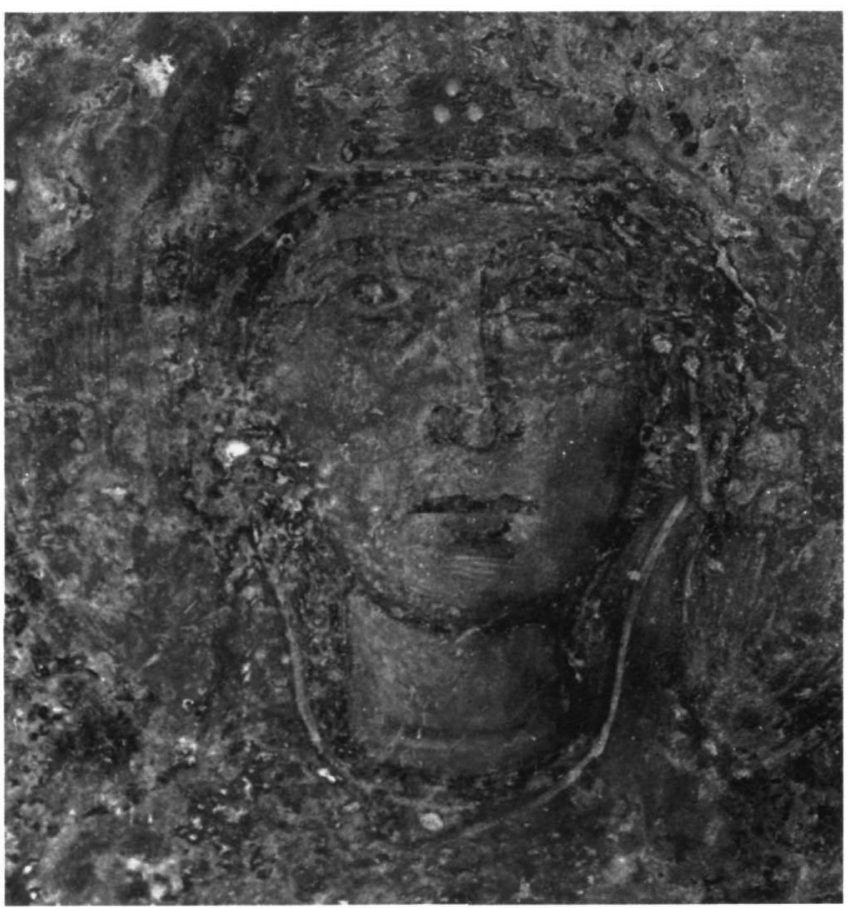




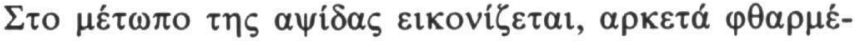

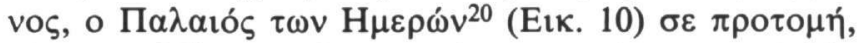

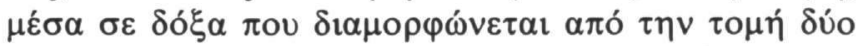

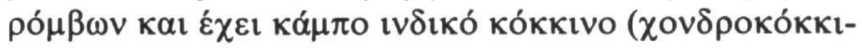

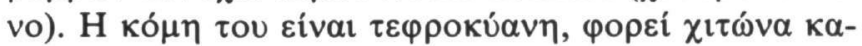

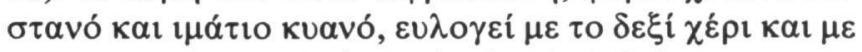

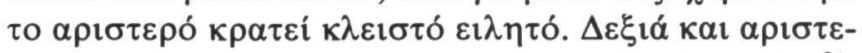

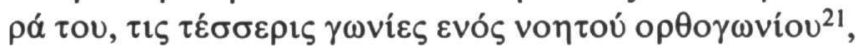

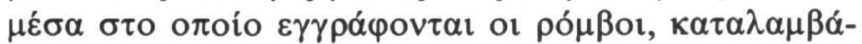

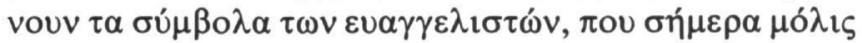

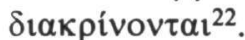

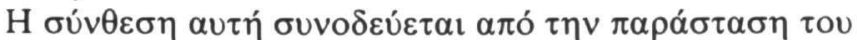

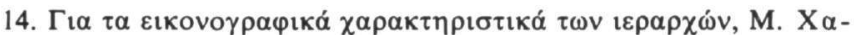

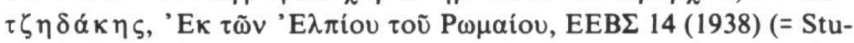
dies in Byzantine Art and Archaeology, Variorum Reprints, London

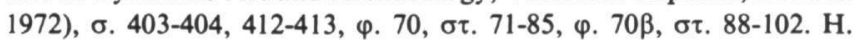
Buchthal, Some Notes on the Byzantine Hagiographical Portraiture,

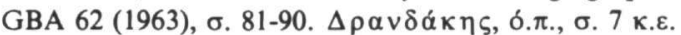

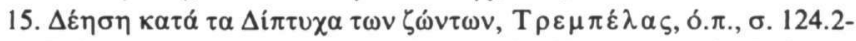

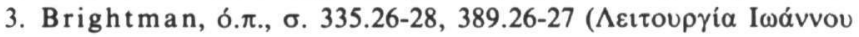

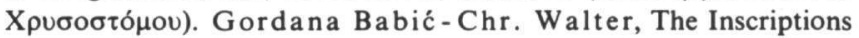
upon Liturgical Rolls in Byzantine Apse Decoration, REB 34 (1976),

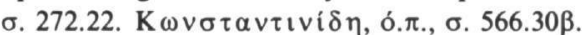

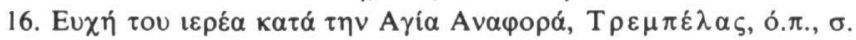

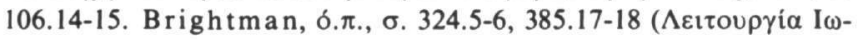

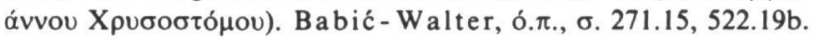

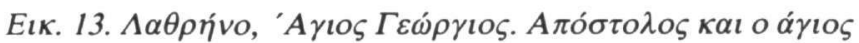

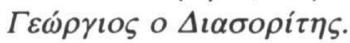

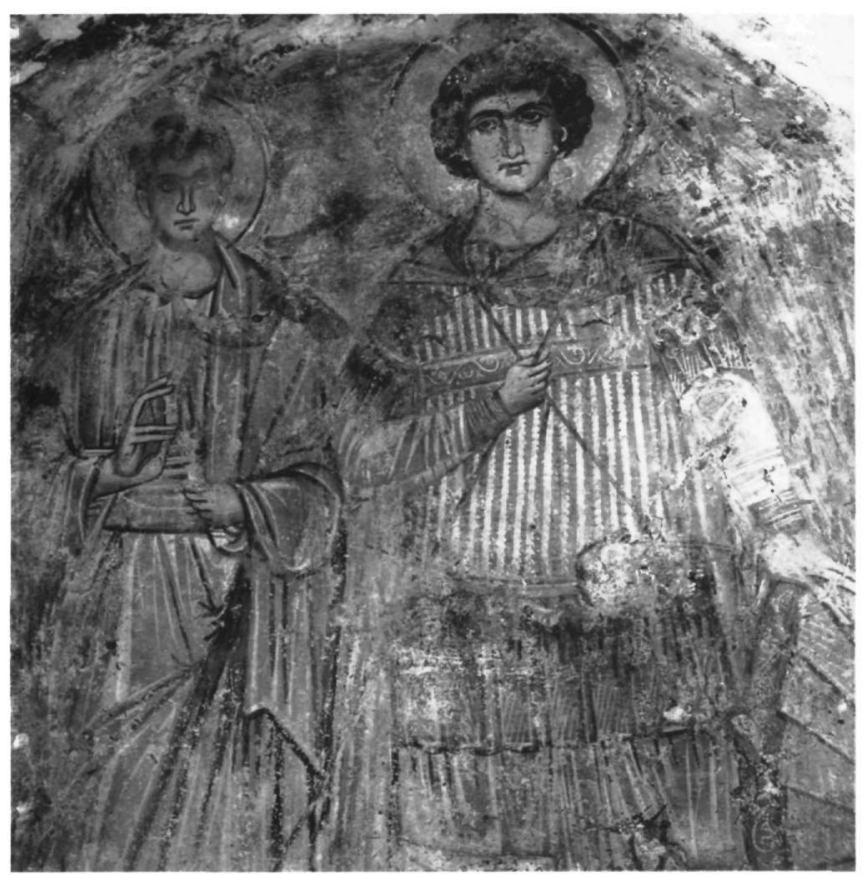

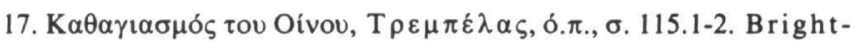

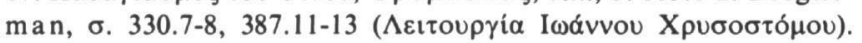

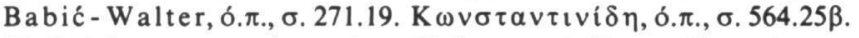

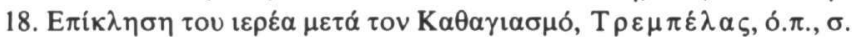

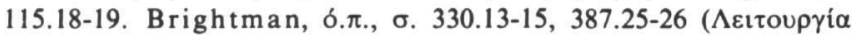

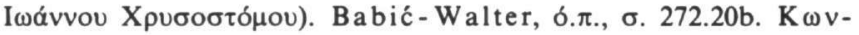
$\sigma \tau \alpha \nu \tau \imath v i \delta \eta, \delta . \pi ., \sigma .565 .26 \beta$.

19. Nicole Thierry, Le costume épiscopal byzantin du XIe au XIIIe siècle, d'après les peintures datées (miniatures fresques), REB XXIV

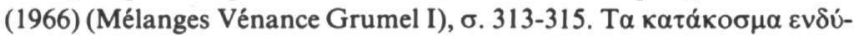

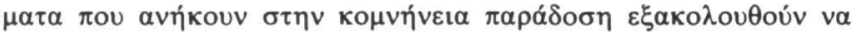

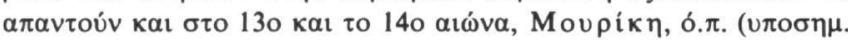
7), б. 103, Sophia Kalopissi-Verti, Die Kirche der Hagia Triada bei Kranidi in der Argolis (1244), München 1975, б. 229 к.E., Anit a Koumoussi, Les peintures murales de la Transfiguration de Pyrgi et

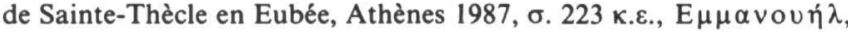

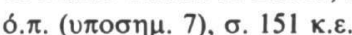

20. $\Delta \alpha \operatorname{vin} \lambda$ Z' 9 к.є. K. Wessel, Christusbild, Der "Alte der Tage",

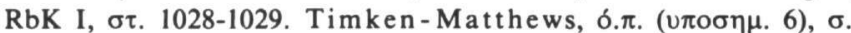

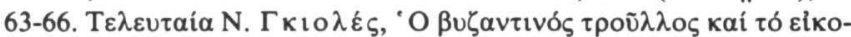

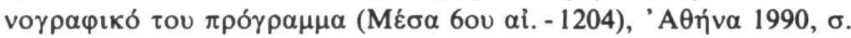

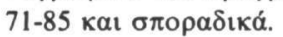

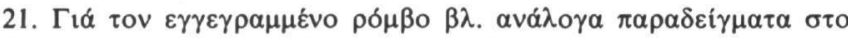

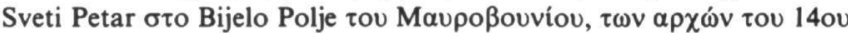
$\alpha \iota \omega \dot{v} \alpha, \mathrm{K}$. Wessel, Das Himmelfahrtsbild von Sveti Petar in Bijelo

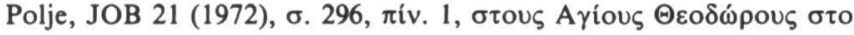

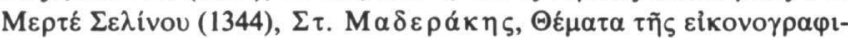

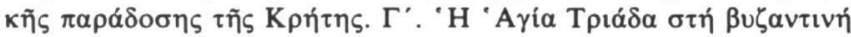

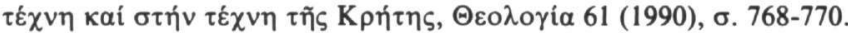

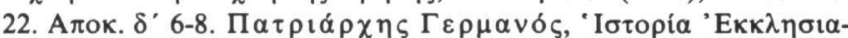

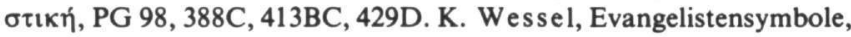

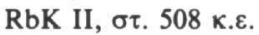

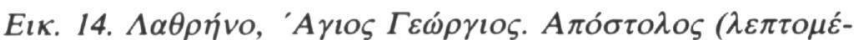
$\rho \varepsilon \iota \alpha \tau \eta \varsigma$ Eıк. 13).

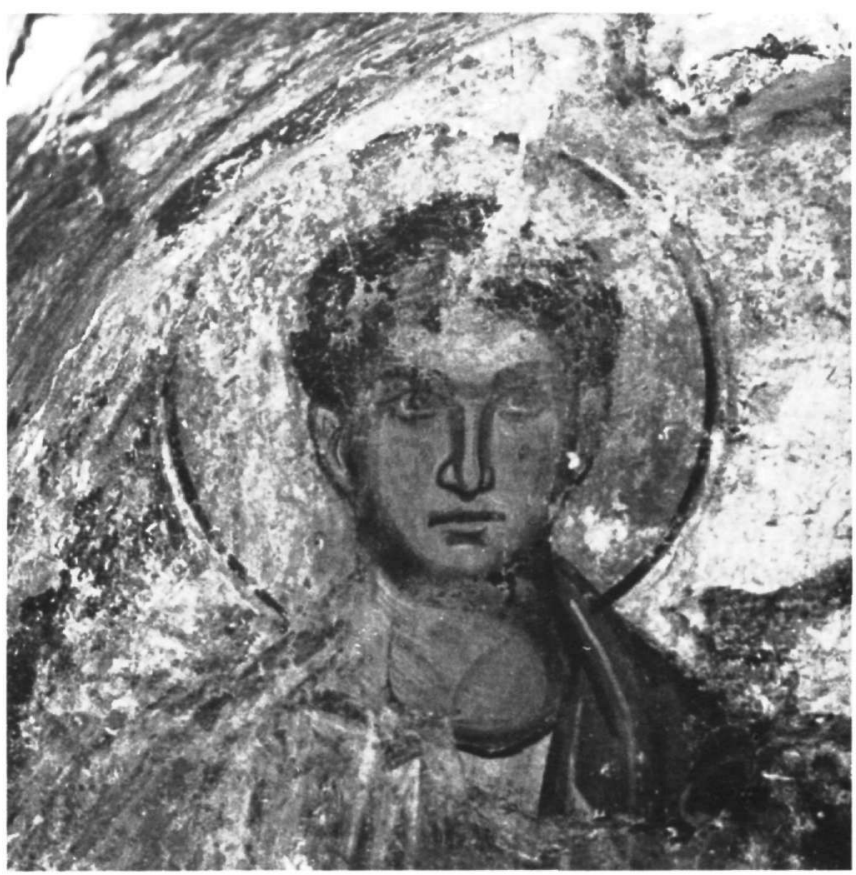




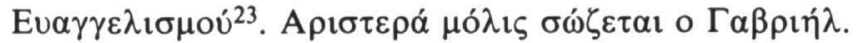
Aлó $\tau \eta \mu \rho \rho \varphi ́$

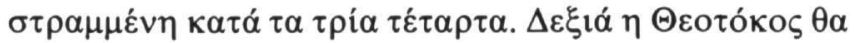

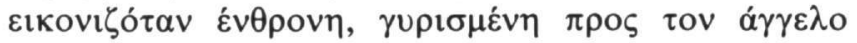

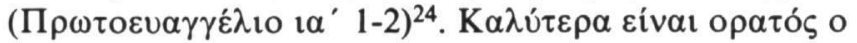

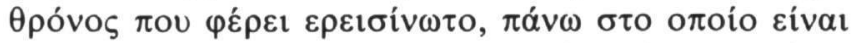

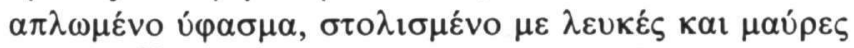

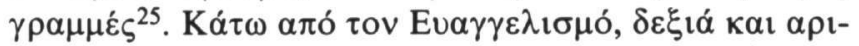

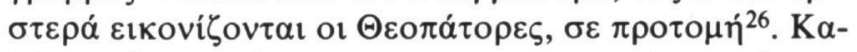

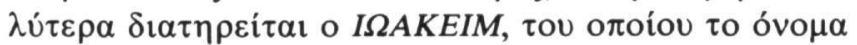

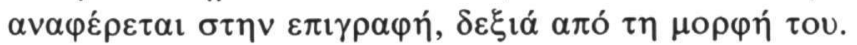

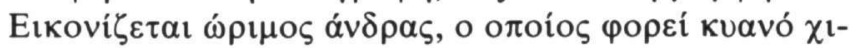

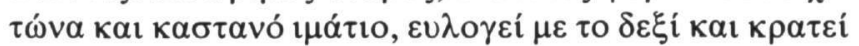

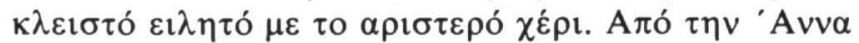

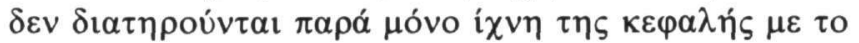

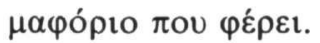

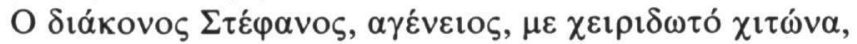

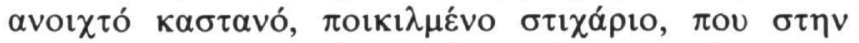

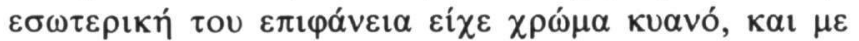

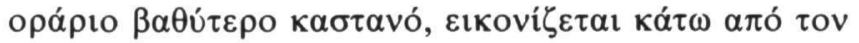

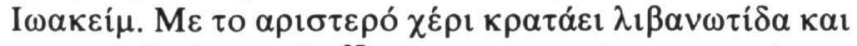

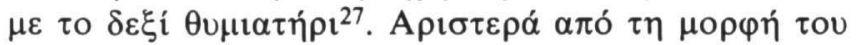

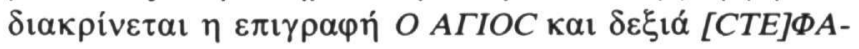

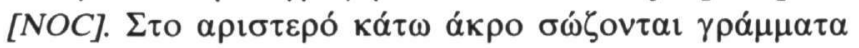

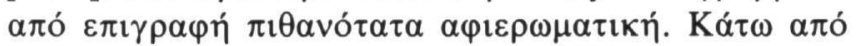

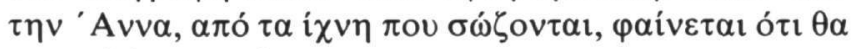
$\varepsilon ı \kappa o v \zeta \zeta o ́ \tau \alpha v ~ \imath \varepsilon \rho \alpha ́ \rho \chi \eta \zeta$.

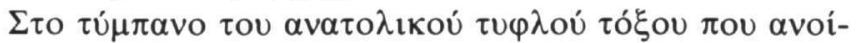

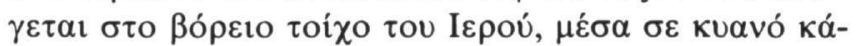

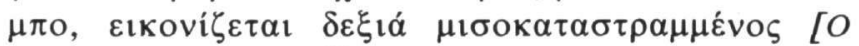

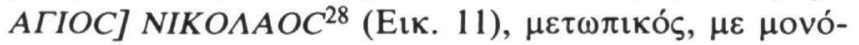

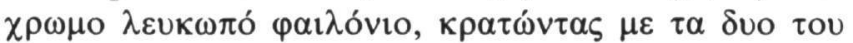

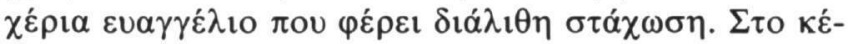

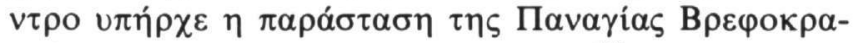

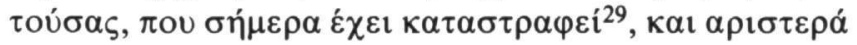

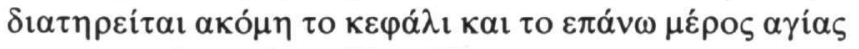

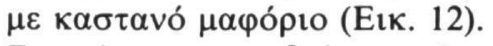

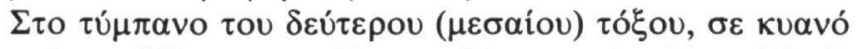

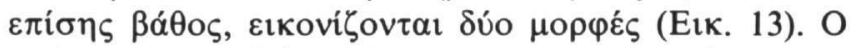

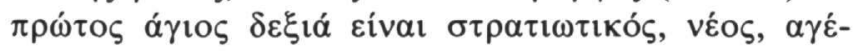

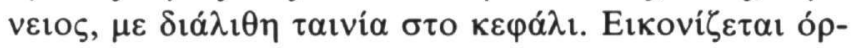

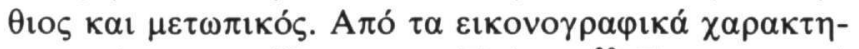

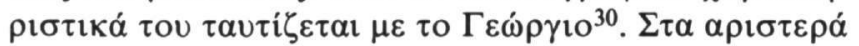

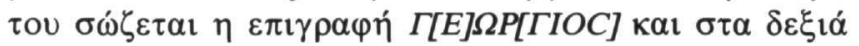

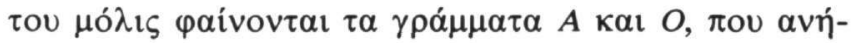

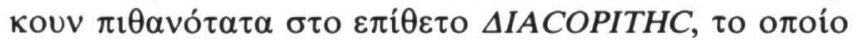

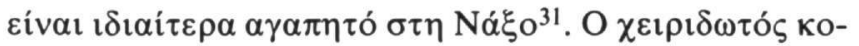

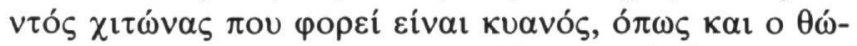

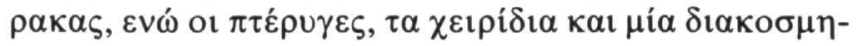

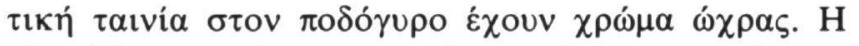

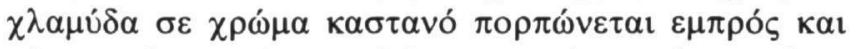

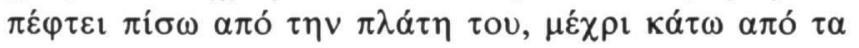

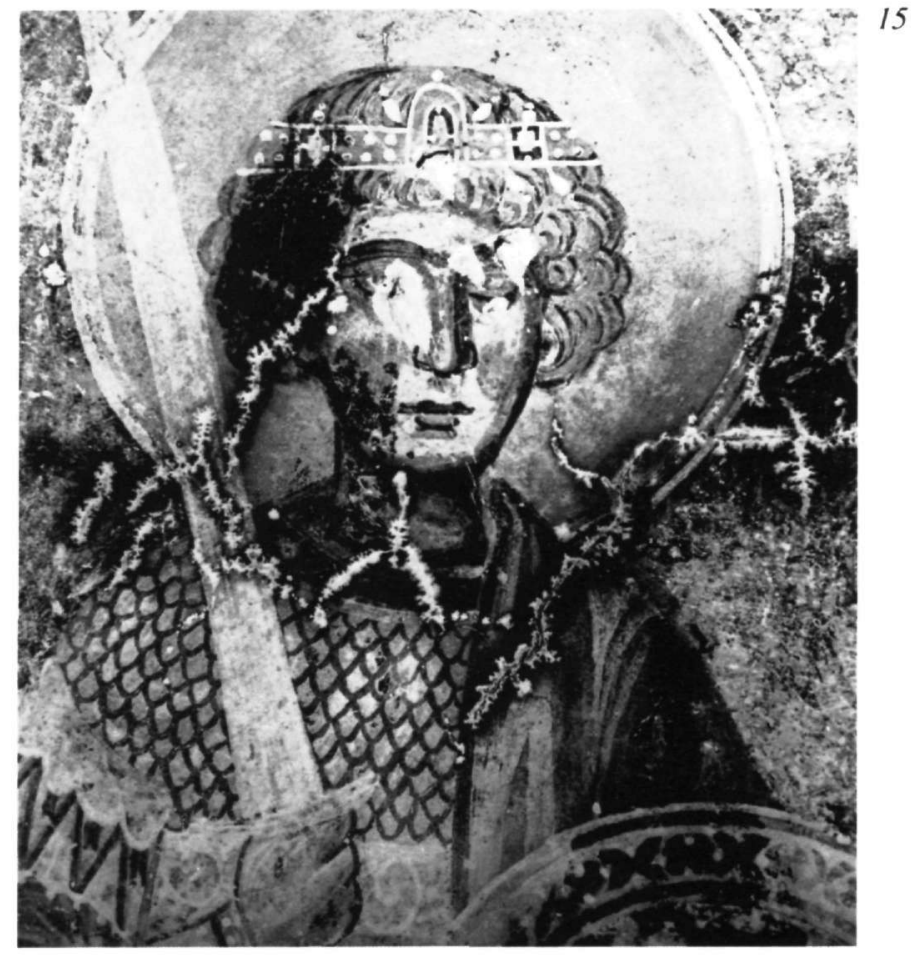

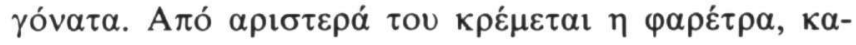

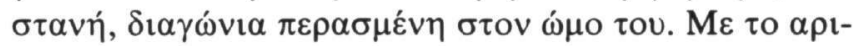

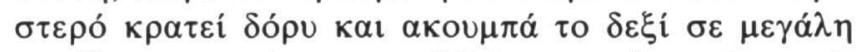

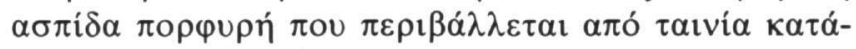
$\kappa о \sigma \mu \eta \sigma \varepsilon \chi \rho \omega ́ \mu \alpha \dot{\omega} \chi \rho \alpha \varsigma$.

A

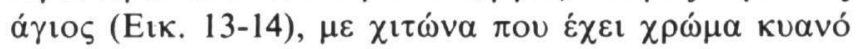

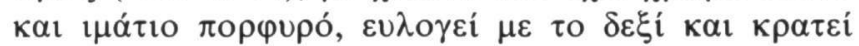

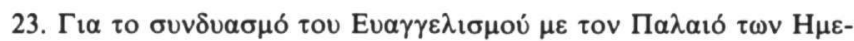
$\rho \omega ́ v$, Theodora Iliopoulou-Rogan, Quelques fresques caractéristiques des églises byzantines du Magne, Byzantion 47 (1977), б. 199

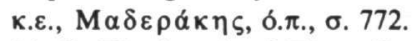

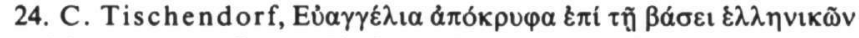

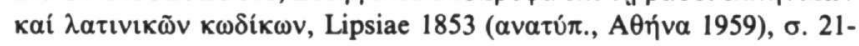
22. G. Millet, Quelques représentations byzantines de la salutation

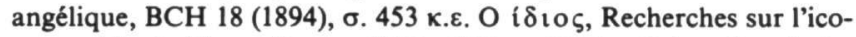
nographie de l'évangile aux XIVe, XVe et XVIe siècles, d'après les monuments de Mistra, de la Macédoine et du Mont Athos, Paris 1916,

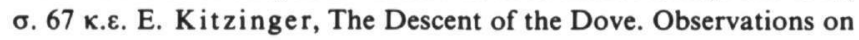
the Mosaic of the Annunciation in the Cappella Palatina in Palermo, Byzanz und der Westen. Studien zur Kunst des europäischen Mittelalters, Wien 1984, б. 99 к.ع.

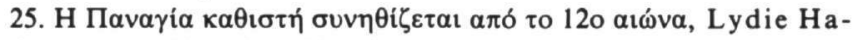
dermann-Misguich, Kurbinovo, Les fresques de Saint-Georges et

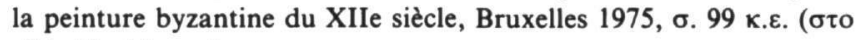
$\varepsilon \xi \tilde{\eta} \varsigma$ Kurbinovo). 
16

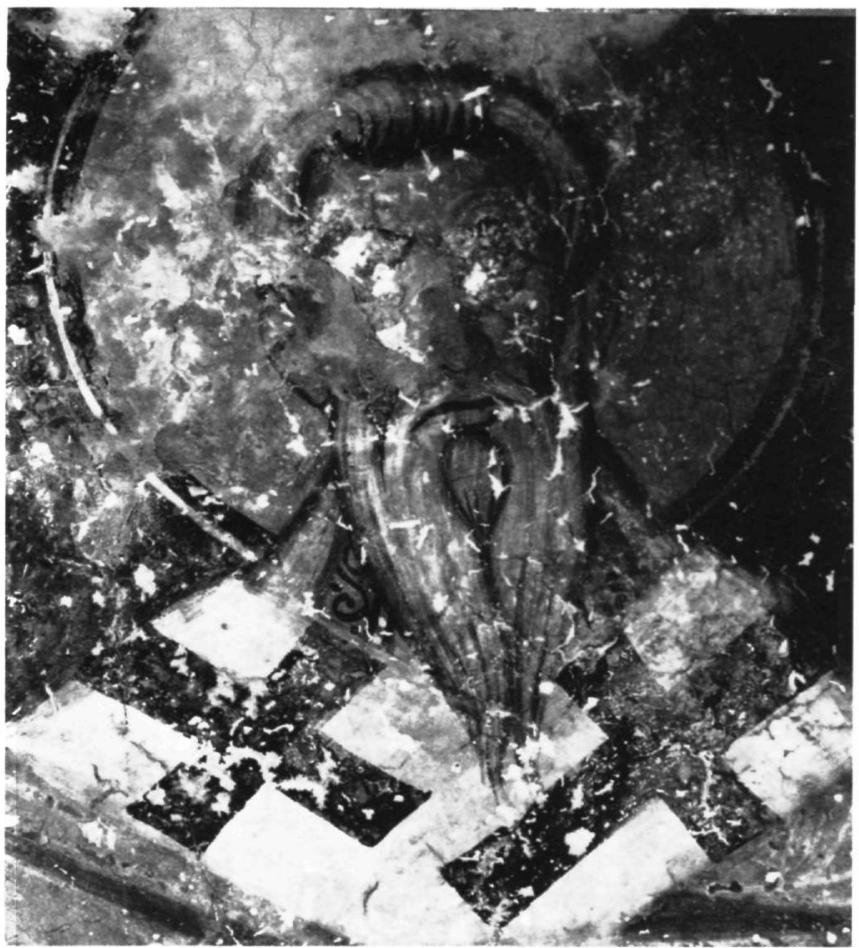

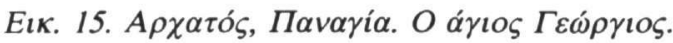

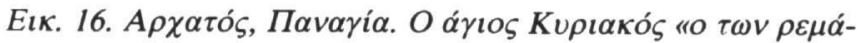
$\tau \omega v \pi \alpha \tau \dot{\eta} \rho »$.

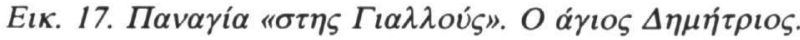

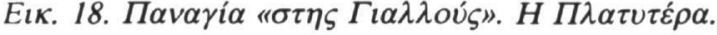

18

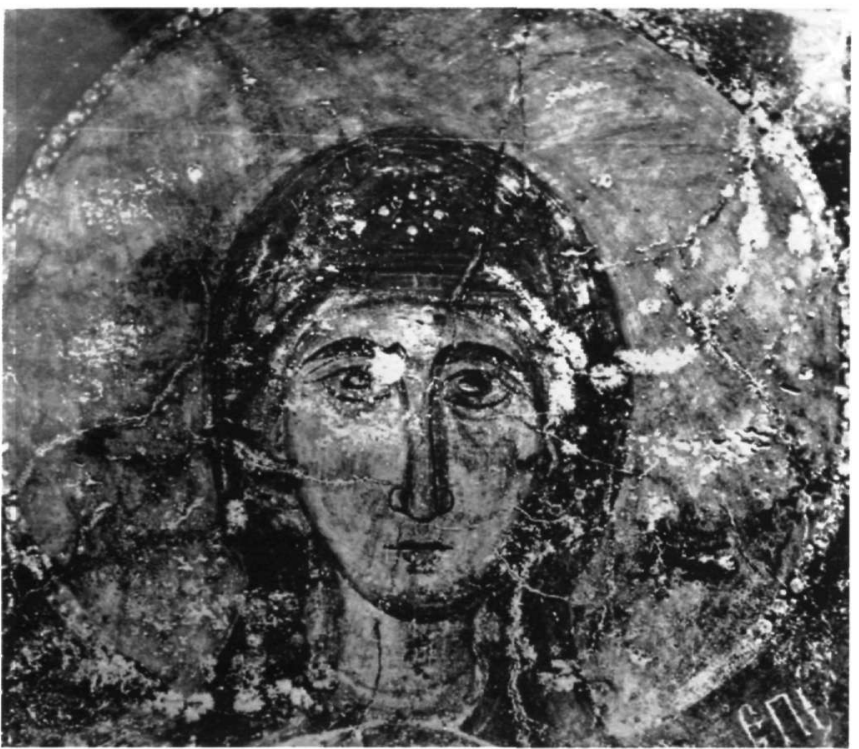

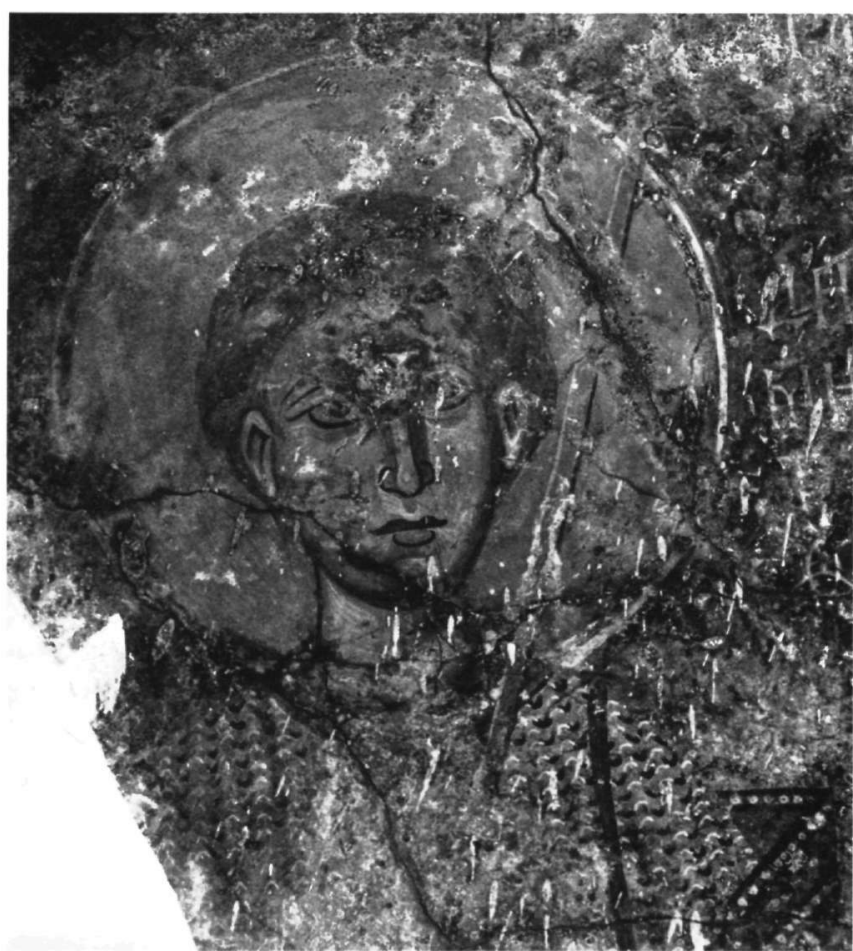

26. П $\alpha \alpha \delta \varepsilon i ́ \gamma \mu \alpha \tau \alpha$ a $\varepsilon \iota \kappa o v i \sigma \varepsilon \omega v$, Jacqueline Lafontaine-Dosogne, Iconographie de l'enfance de la Vierge dans l'empire byzantin

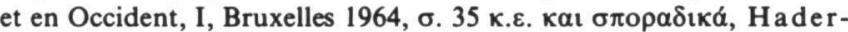

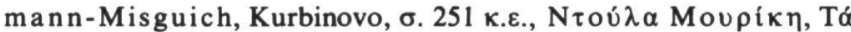

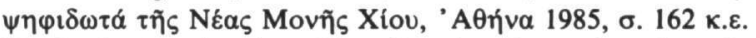

27. G. de Jerphanion, L'attribut des diacres dans l'art chrétien du

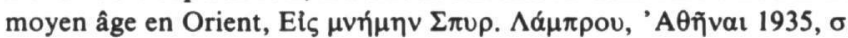
403 к.ع. (=La voix des monuments, Nouv. Série, Roma-Paris 1938, $\sigma$.

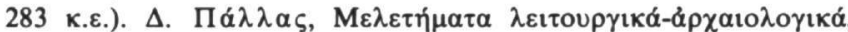

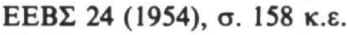

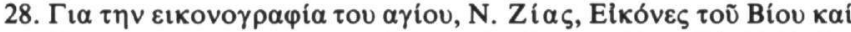

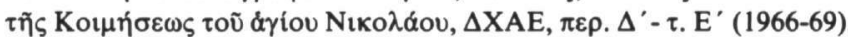

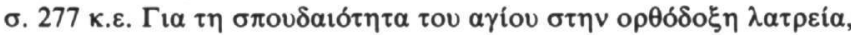
G. Anrich, Hagios Nikolaos. Der heilige Nikolaos in der griechischen Kirche, I-II, Leipzig 1913-1917, Nancy Ševěenco, The Life of Saint Nicholas in Byzantine Art, Torino 1983, б. 161-162, 173.

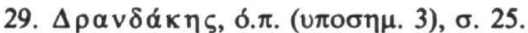

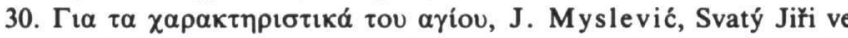

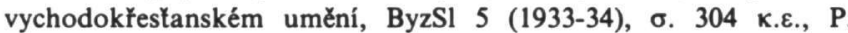
Underwood, Fourth Preliminary Report on the Restoration of the Frescoes in the Kariye Camii at Istanbul by the Byzantine Institute, DOP 13 (1959), б. 189-191, Hadermann-Misguich, Kurbinovo, $\sigma$.

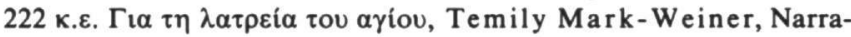
tive Cycles of the Life of Saint George in Byzantine Art, I-II (Ph. D.), New York University 1977, $\sigma .1-20$.

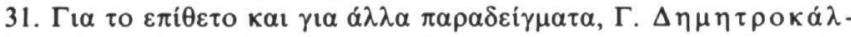

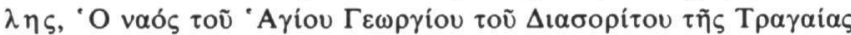

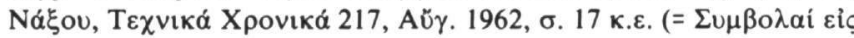

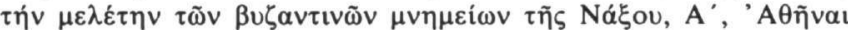

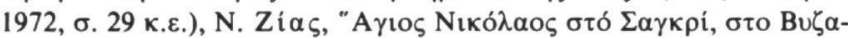

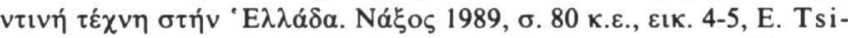
ga ridas, La peinture à Kastoria et en Macédoine grecque occidentale vers l'année 1200. Fresques et icônes, Studenica et l'art byzantin au-

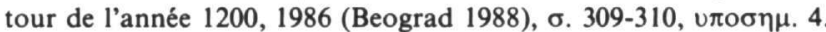




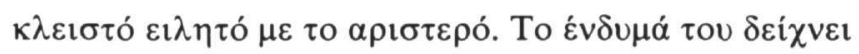

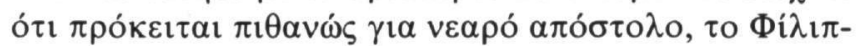

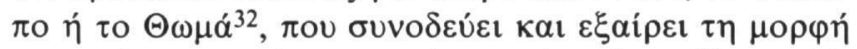

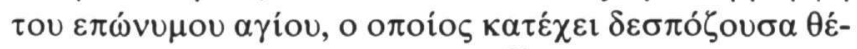

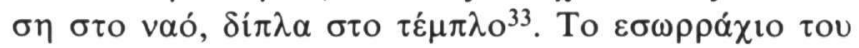

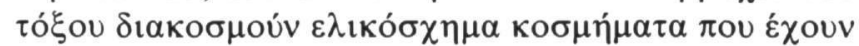

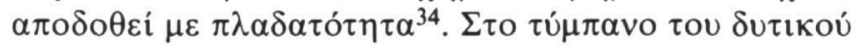

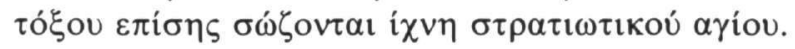

\section{Eккоvоүрачі́a}

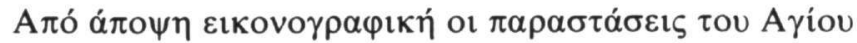

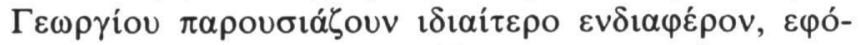

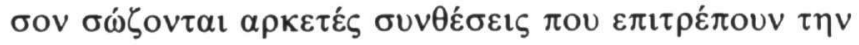

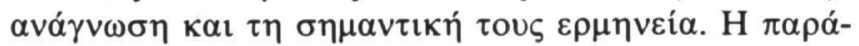

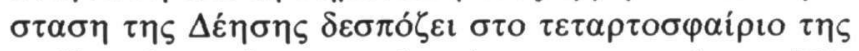

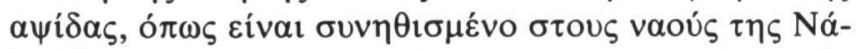

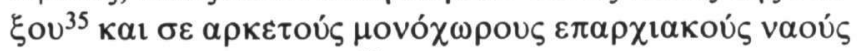

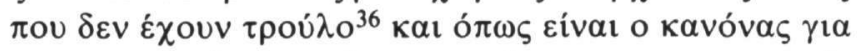

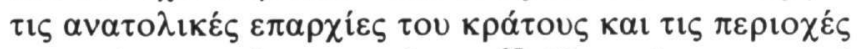

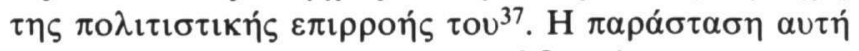

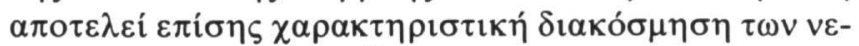
$\kappa \rho \iota \kappa \dot{v} v \pi \alpha \rho \varepsilon \kappa \kappa \lambda \eta \sigma i \omega v^{38}$.

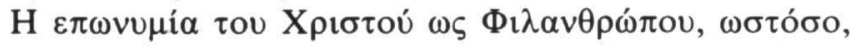

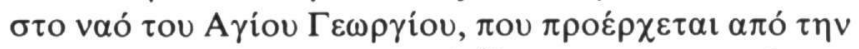

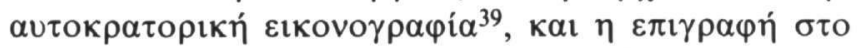

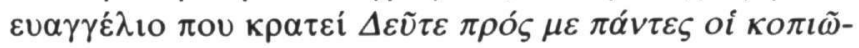

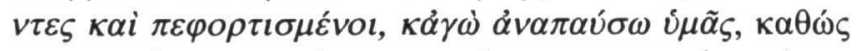

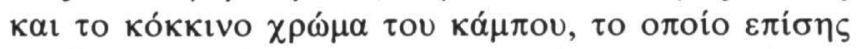

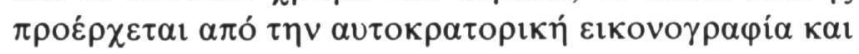

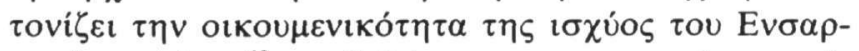

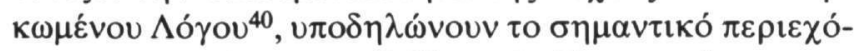

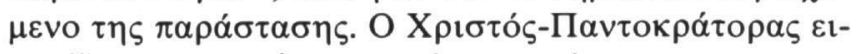

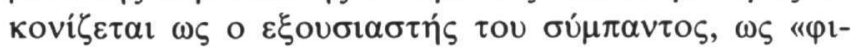

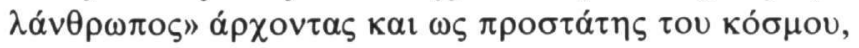

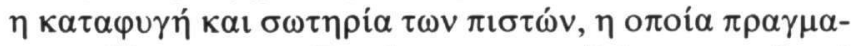

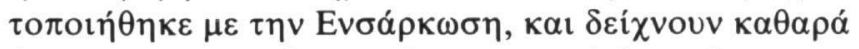

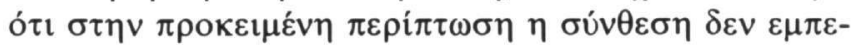

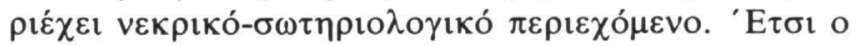

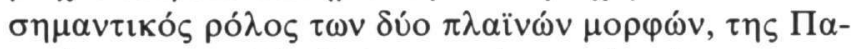

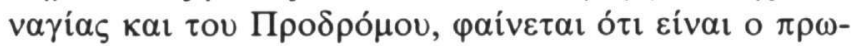

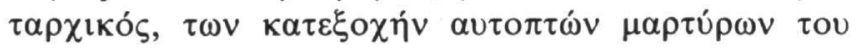

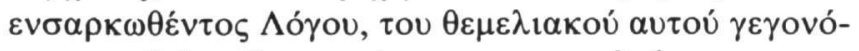

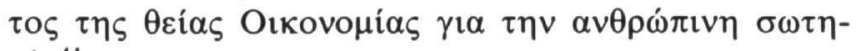
pía $\alpha^{4 !}$.

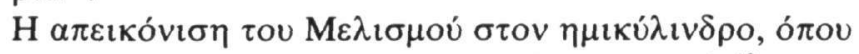

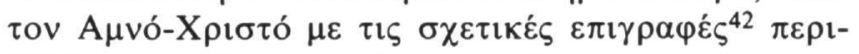

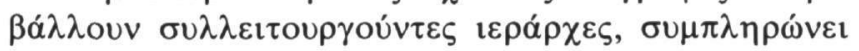

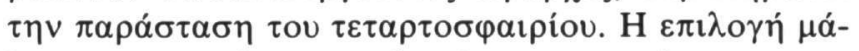

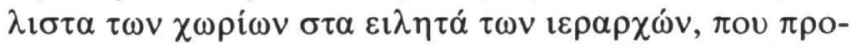

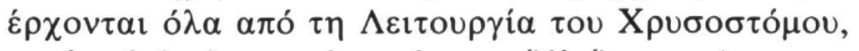

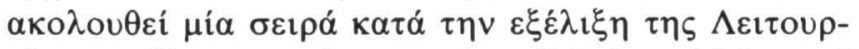

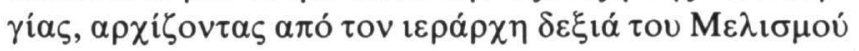

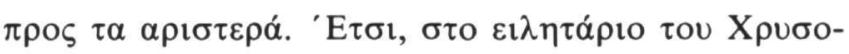

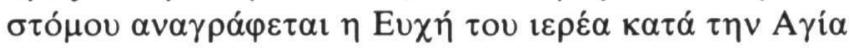

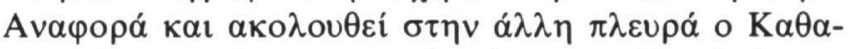

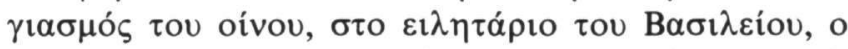

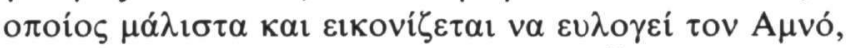

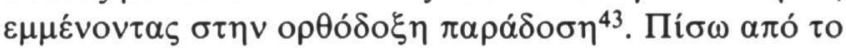

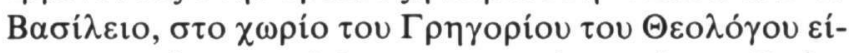

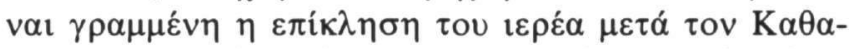

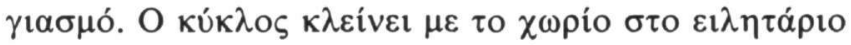

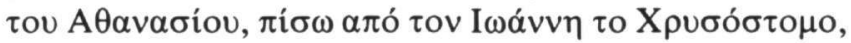

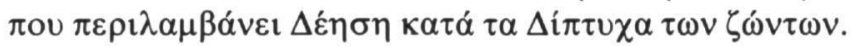

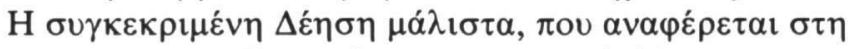

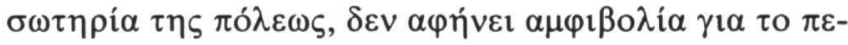

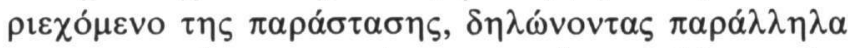

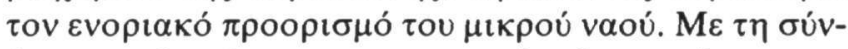

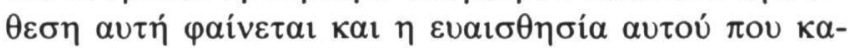

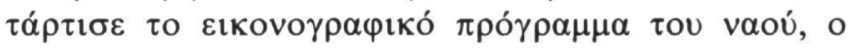

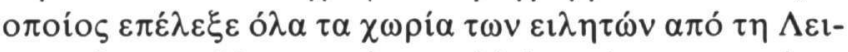

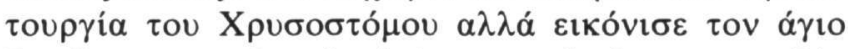

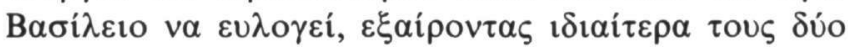

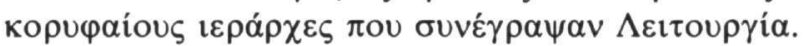

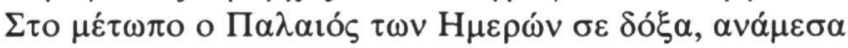

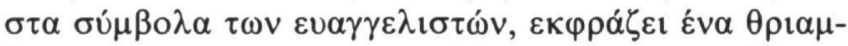

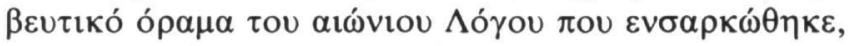

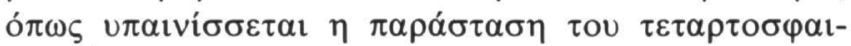

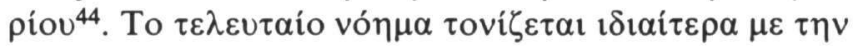

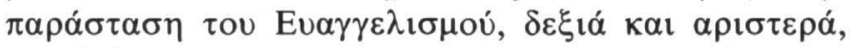

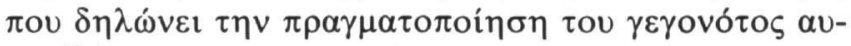

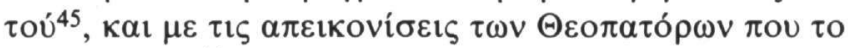

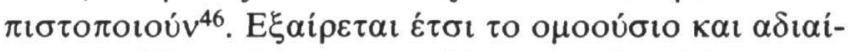

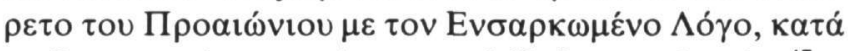

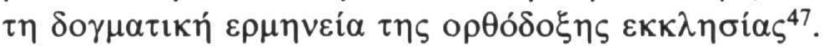

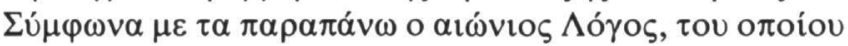

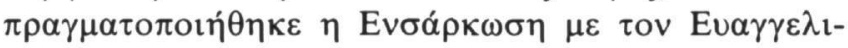

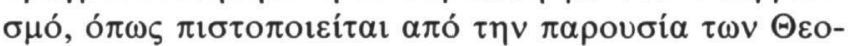

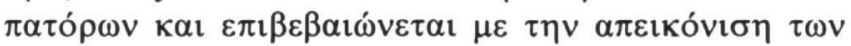

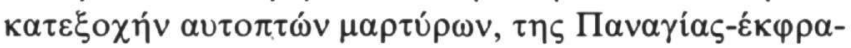

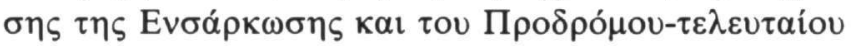

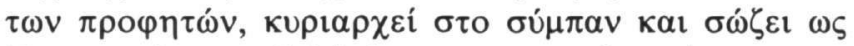

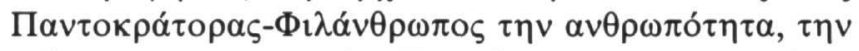

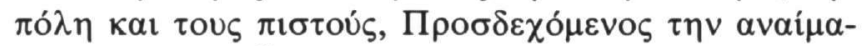

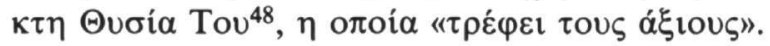

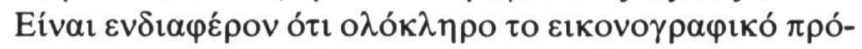

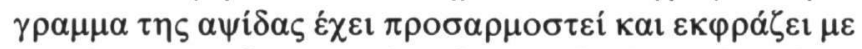

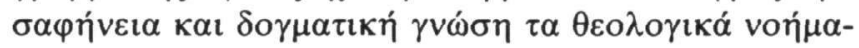

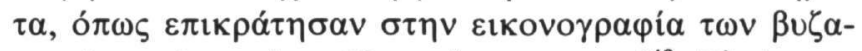

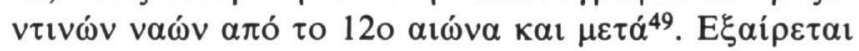

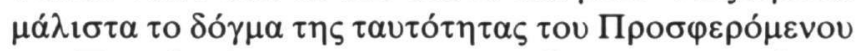

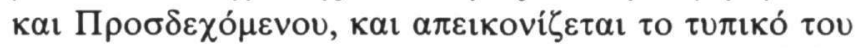

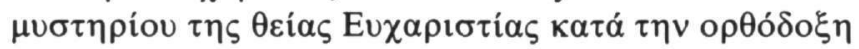

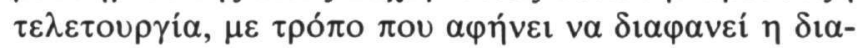

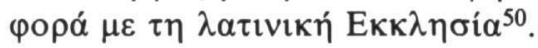




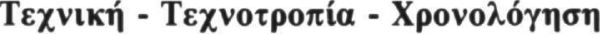

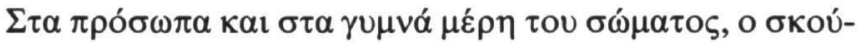

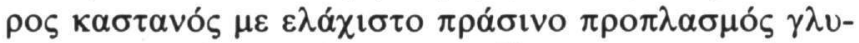

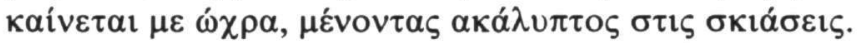

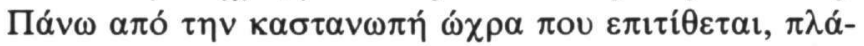

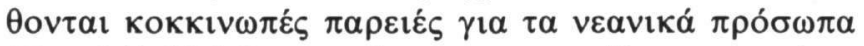

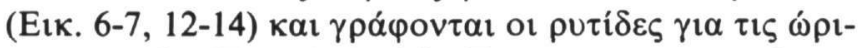

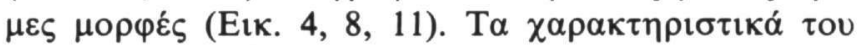

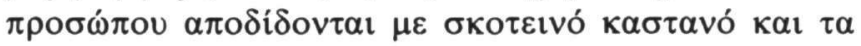

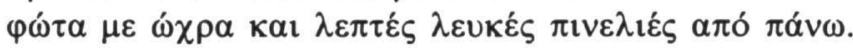

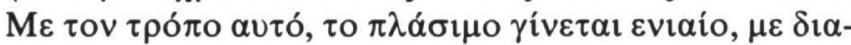

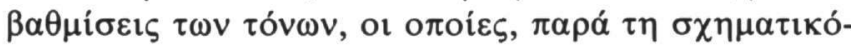

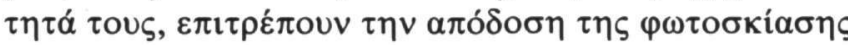

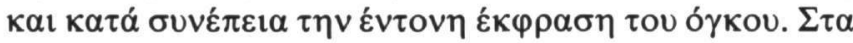

32. G. de Jerphanion, Quels sont les douze apôtres dans l'iconographie chrétienne, La voix des monuments, Paris 1930, б. 191-196. K. Wessel, Apostel, RbK I, $\sigma \tau .238$.

33. A. Grabar, Deux notes sur l'histoire de l'iconostase d'après des monuments de Yougoslavie, ZRVI 7 (1961), б. 21-22 (= L'art de la fin de l'antiquité et du moyen âge, I, Paris 1968, б. 410-411). Gordana Babić, O živopisanom ukrasu oltarskin pregrada, ZLU 11 (1975), $\gamma \alpha \lambda \lambda$. $\pi \varepsilon \rho i \lambda \eta \psi \eta \sigma .42-44$. M. Chatzidakis, L'évolution de l'icône aux $11 \mathrm{e}-13 \mathrm{e}$ siècles et la transformation du templon, Actes, XVe Congrès International d'études byzantines, Athènes 1976, I (1979), $\sigma .337$.

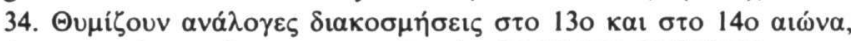

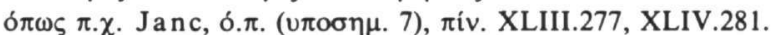

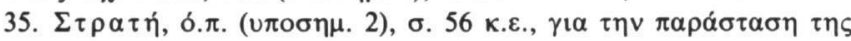

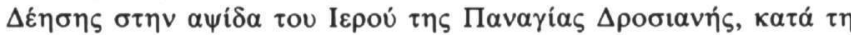

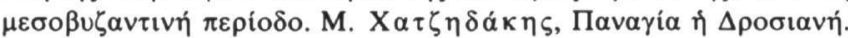

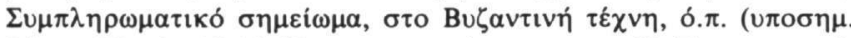

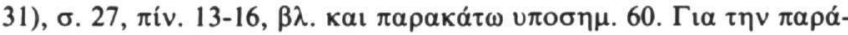

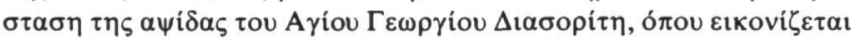

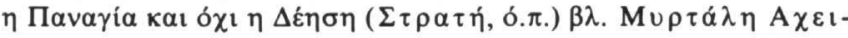

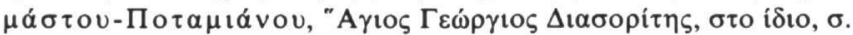
$67, \varepsilon 1 \kappa .1,4$.

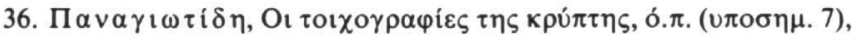

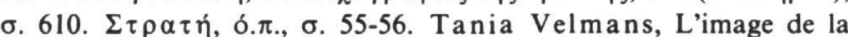
Déisis dans les églises de Georgie et dans celles d'autres regions du monde byzantin, CahArch 29 (1980-81), o. 57-58, 63, 66. Alba Medea, Gli affreschi delle cripte eremitiche pugliesi, I-II, Roma 1939, $\sigma \pi \mathrm{o} \alpha \delta \delta$ เ

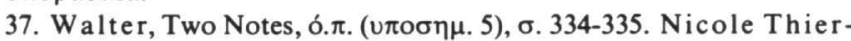
ry, A propos des peintures d'Ayvali Köy (Cappadoce). Les programmes absidaux à trois registres avec Déisis, en Cappadoce et en Georgie,

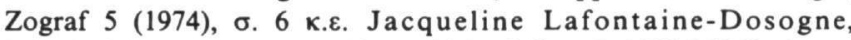
L'évolution du programme décoratif des églises de 1071 à 1261, Actes, XVe Congrès International d'études byzantines, Athènes 1976, I

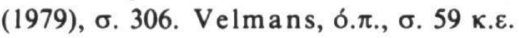

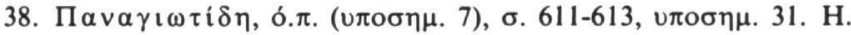
Belting-C. Mango-Doula Mouriki, The Mosaics and Frescoes of St. Mary Pammakaristos (Fetiye Camii) at Istanbul, Washington

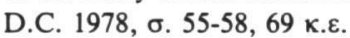

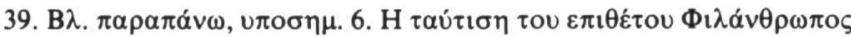

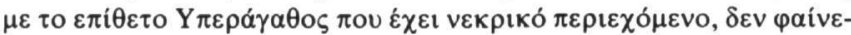

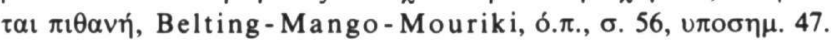

40. A. Kazhdan-S. Fraklin, Studies on Byzantine Literature of the

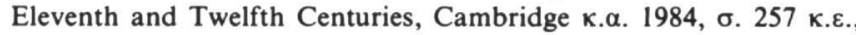

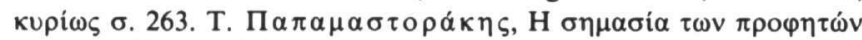

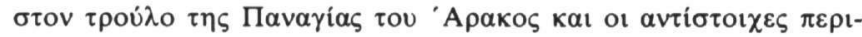

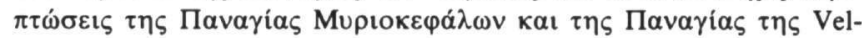

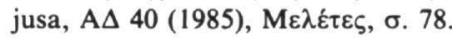

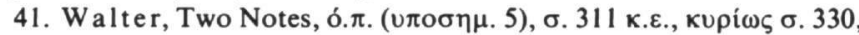

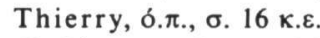

42. B $\lambda . \pi \alpha \rho \alpha \pi \alpha ́ v \omega, \sigma .143$

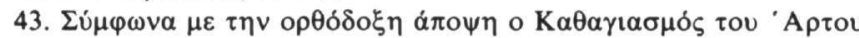

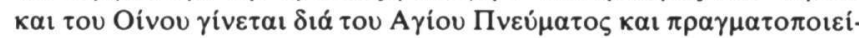

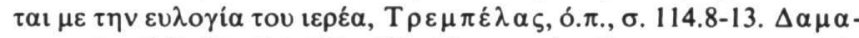

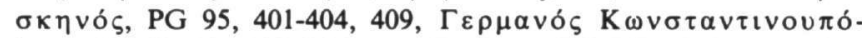

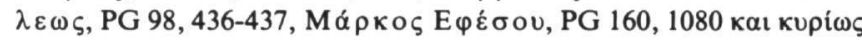

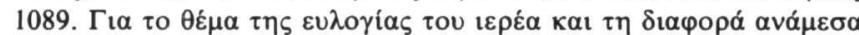

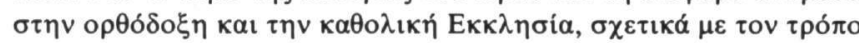

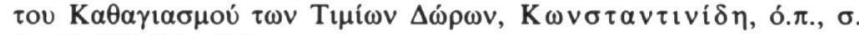
60-62, 270-271, 424.

44. K. $\Delta$ טoßouvเ

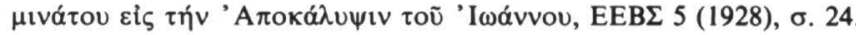

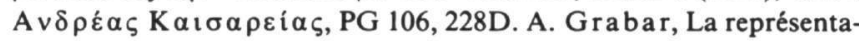
tion de l'intelligible dans l'art byzantin du moyen âge, Actes VIe Congrès International des études byzantines, Paris 1948, II (1950), $\sigma$. 131-135 (= L'art de la fin de l'antiquité et du moyen âge, I, Paris 1968, $\sigma .54-57)$. Tamar Avner, The Impact of the Liturgy on Style and Content. The Triple-Christ Scene in Paphou 14, JÖB 32/5 (1982) (= XVI. Internationaler Byzantinistenkongress, Akten II/5), б. 464-465. 45. D. Pallas, Die Passion und Bestattung Christi in Byzanz. Der

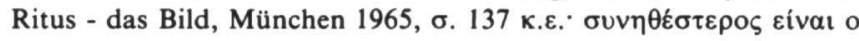

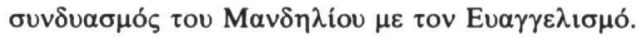

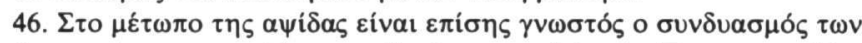

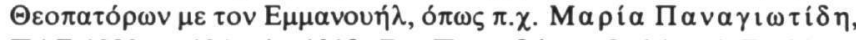

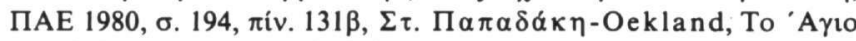

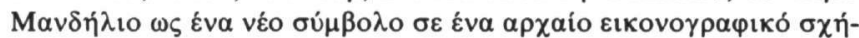

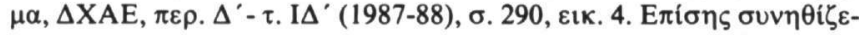

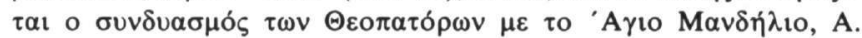
Grabar, La Sainte Face de Laon. Le Mandylion dans l'art orthodo-

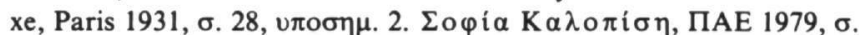

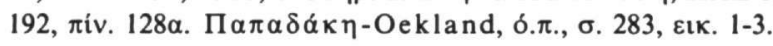

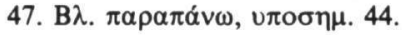

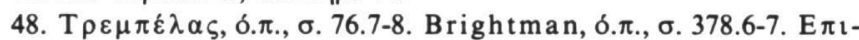

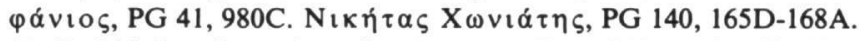

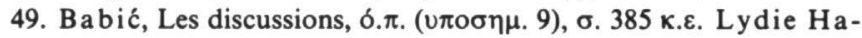
derman-Misguich, Fresques de Chypre et de Macédoine dans la

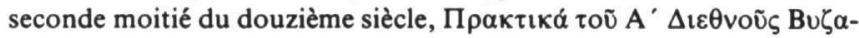

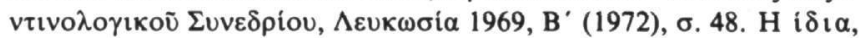
Kurbinovo, $\sigma .70$ к.ع. Nafsika Coumbaraki-Panselinou, SaintPierre de Kalyvia-Kouvara et la chapelle de la Vierge de Mérenta.

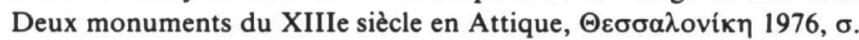
56-58. M. Garidis, Approche "réaliste" dans la représentation du Melismos, JÖB 32/5 (1982) (= XVI. Internationaler Byzantinistenkongress, Akten II/5), б. 495 к.E. A. Lidov, Christ as the Priest in Byzantine Church Decoration of the 11th and 12th Centuries, XVIIIe Congrès International des études byzantines, Moscou 1991, Résumés des Communications, II, $\sigma .659-660$.

50. J. Gouillard, Le synodikon de l'Orthodoxie: édition et commen-

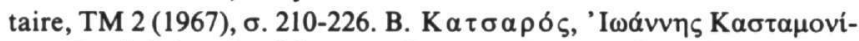

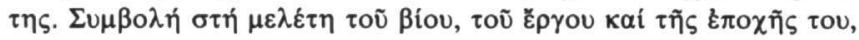

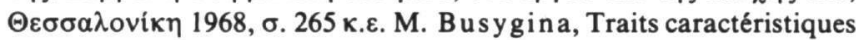
de christologie byzantine en XI-XII ss., XVIIIe Congrès International des études byzantines, Moscou 1991, Résumés des Communications I, б. 192-193. 


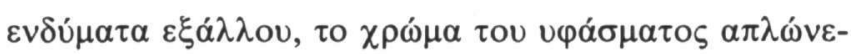

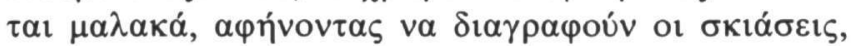

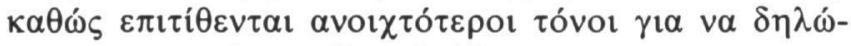

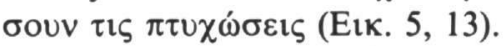

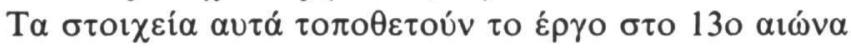

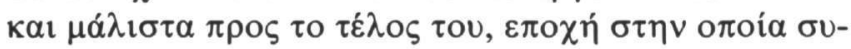

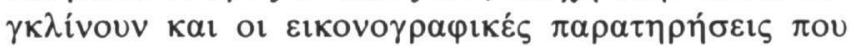

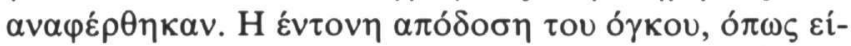

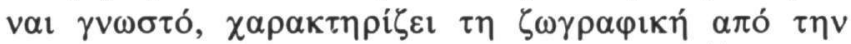

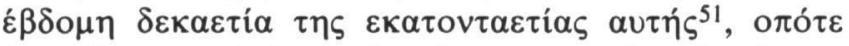

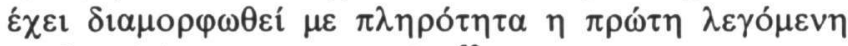
" $\left.\pi \alpha \lambda \alpha 10 \lambda o ́ \gamma \varepsilon 1 \alpha \tau \varepsilon \chi v o \tau \rho \circ \pi \alpha_{\alpha}\right)^{52}$.

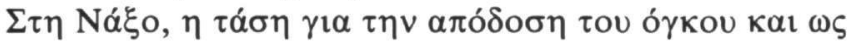

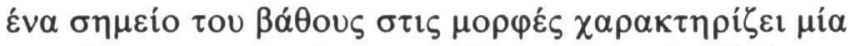

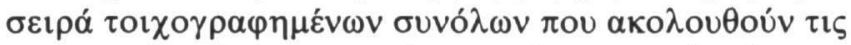

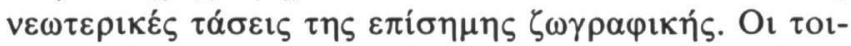

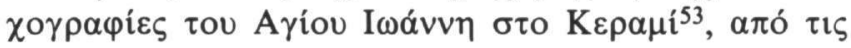

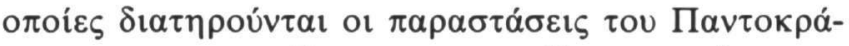

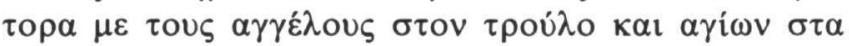

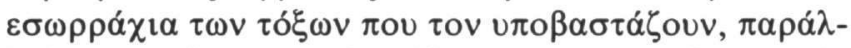

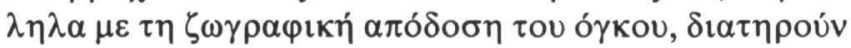

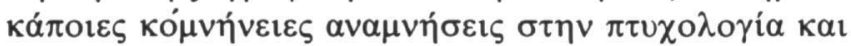

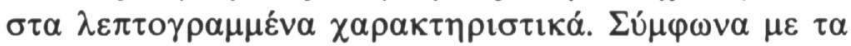

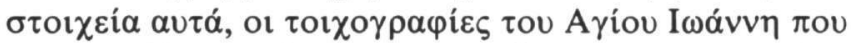

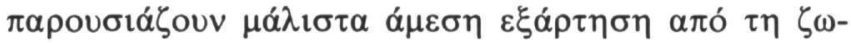

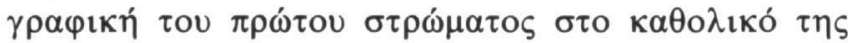

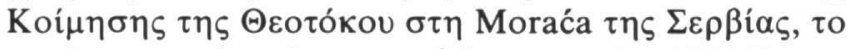
o

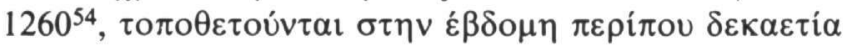

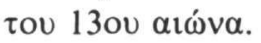

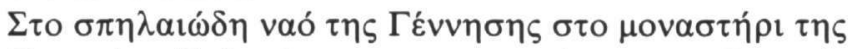

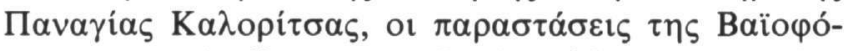

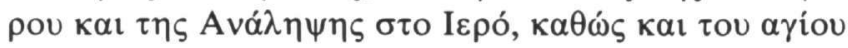

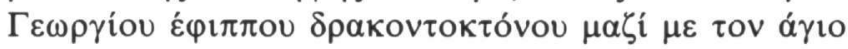

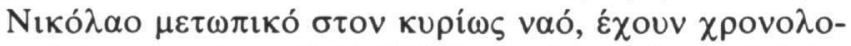

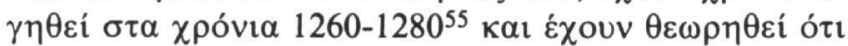

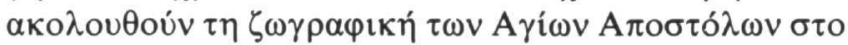

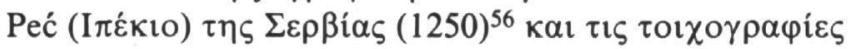

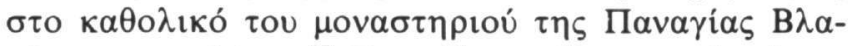

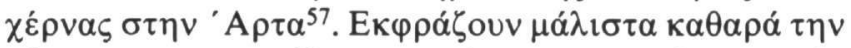

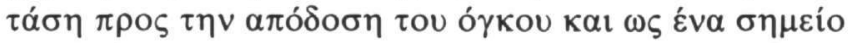

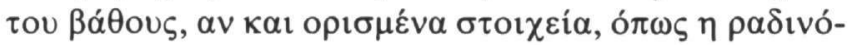

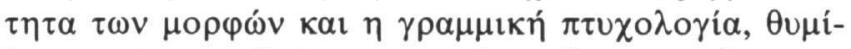

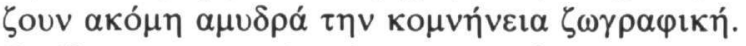

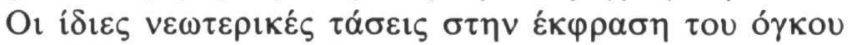

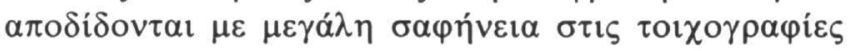

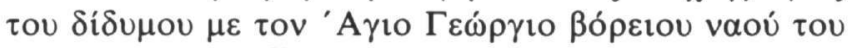

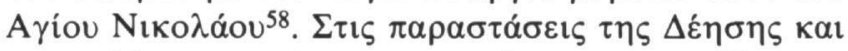

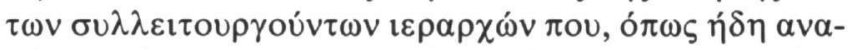

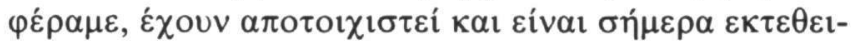

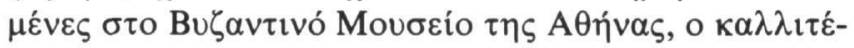

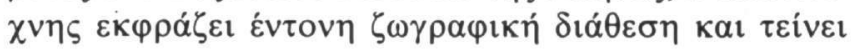

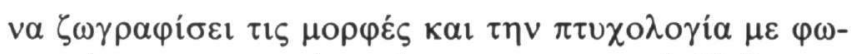

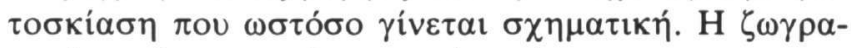

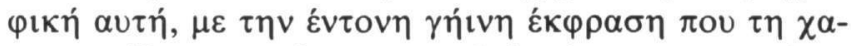

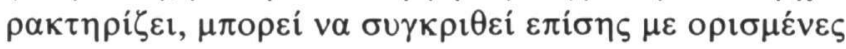

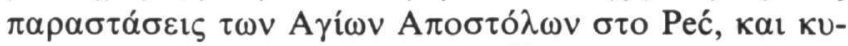

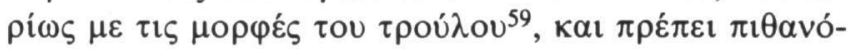

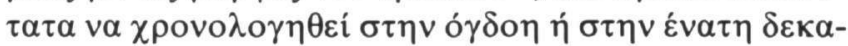

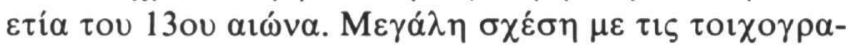

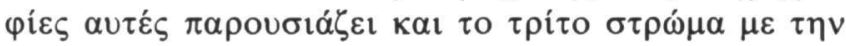

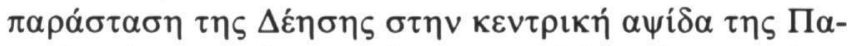

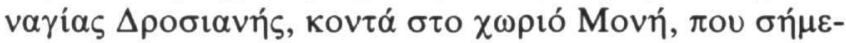

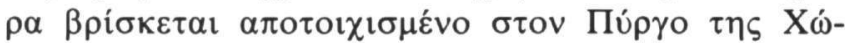

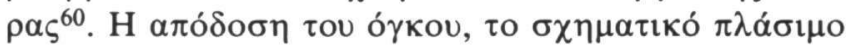

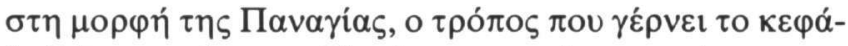

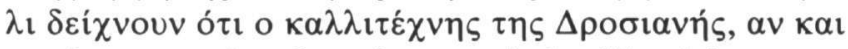

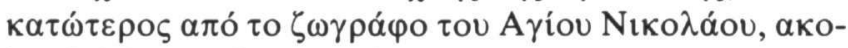

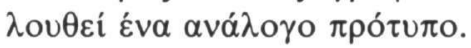

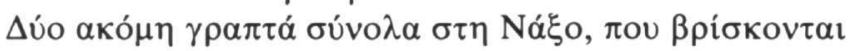

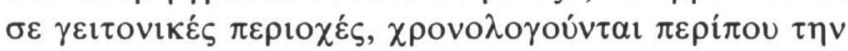

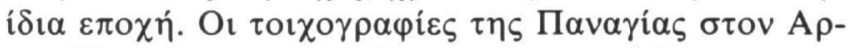

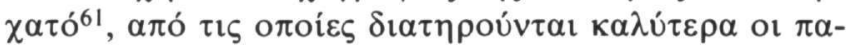

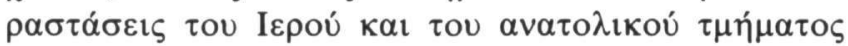

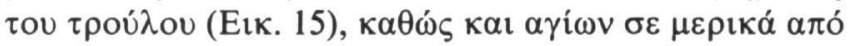

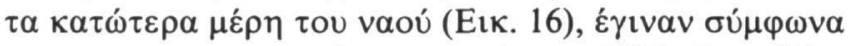

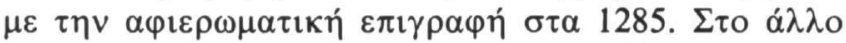

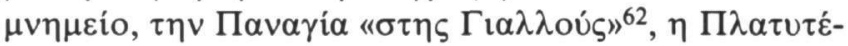

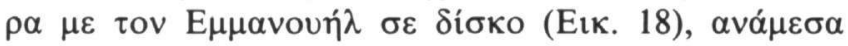

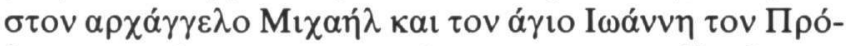

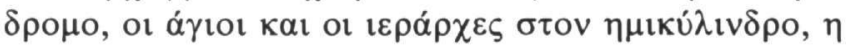

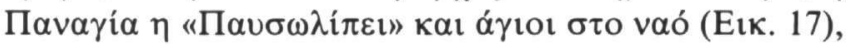

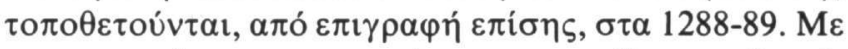

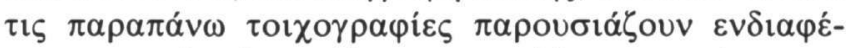

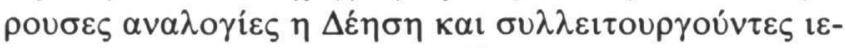

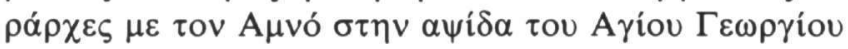

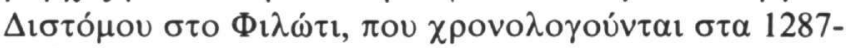

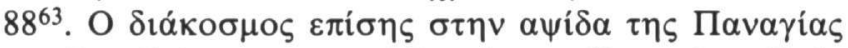

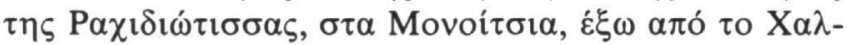

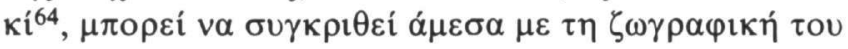

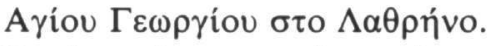

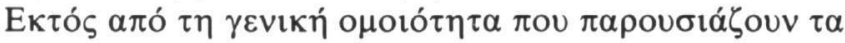

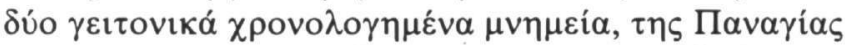

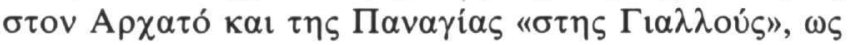

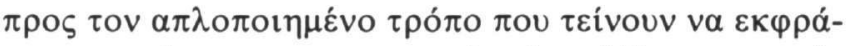

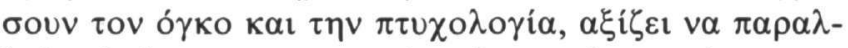

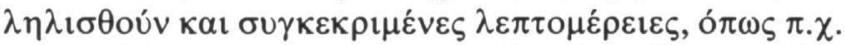

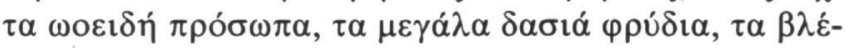

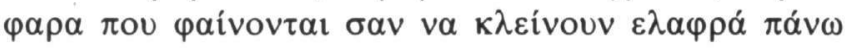

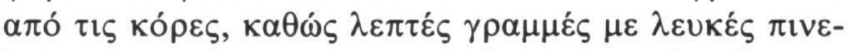

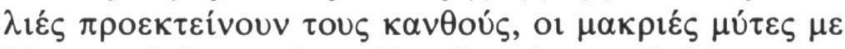

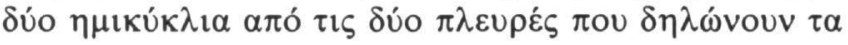

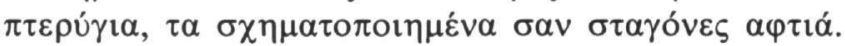

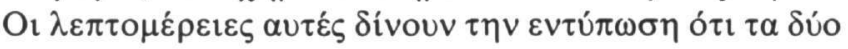




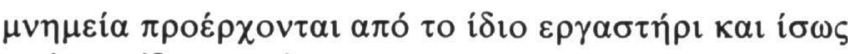
$\alpha \pi$ tov ísto $\tau \varepsilon \chi v i ́ \tau \eta$.

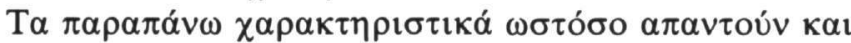

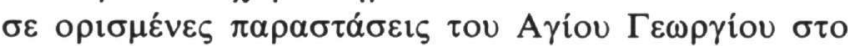

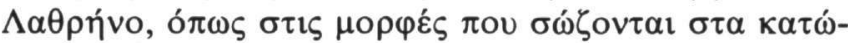

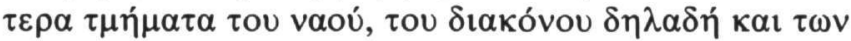

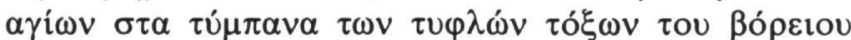

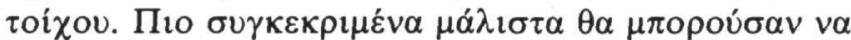

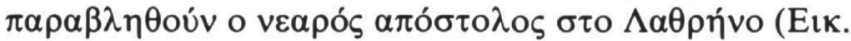

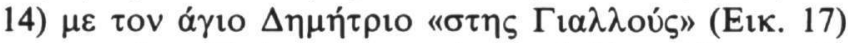

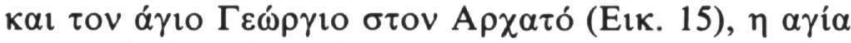

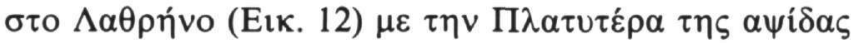

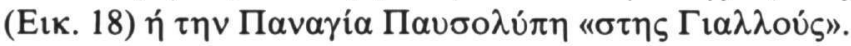

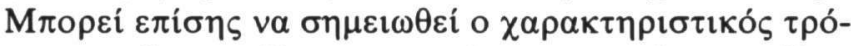

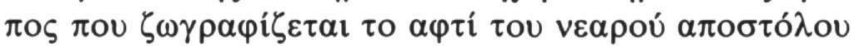

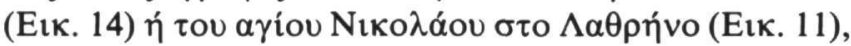

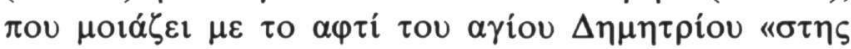

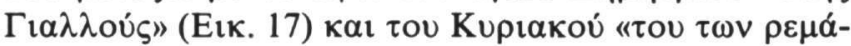

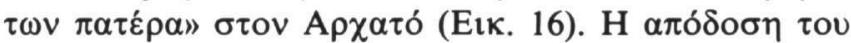

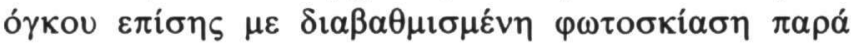

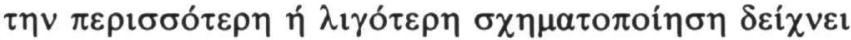

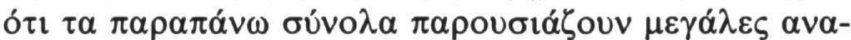

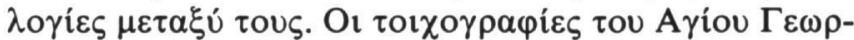

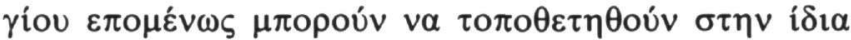

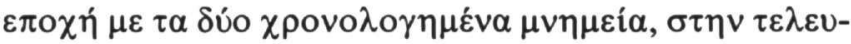

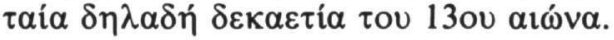

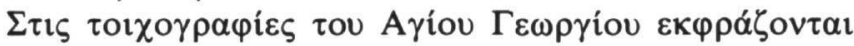

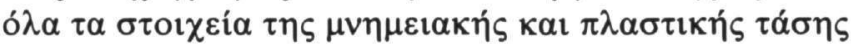

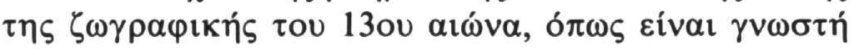

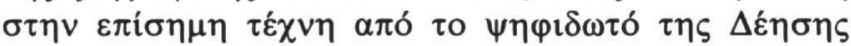

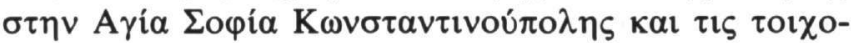

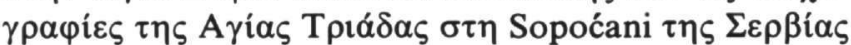

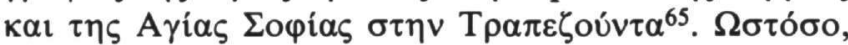

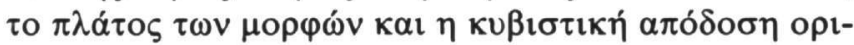

51. M. Chatzidakis, Aspects de la peinture murale du XIIIe siècle en Grèce, L'art byzantin du XIIIe siècle. Symposium de Sopoćani

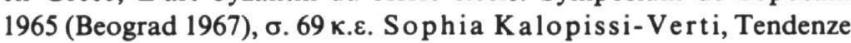
stilistiche della pittura monumentale in Grecia durante il XIII secolo, CorsiRav 31 (1984), б. 232 к.ع.

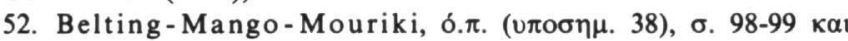
טлобๆ 4.49.

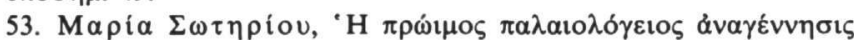

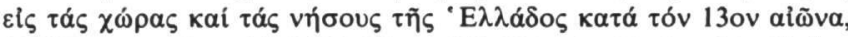
$\Delta$ XAE, $\pi \varepsilon \rho . \Delta^{\prime}-\tau . \Delta^{\prime}(1964-65), \sigma .263-264, \pi i v$. 56. Sophia Kalopissi-Verti, Osservazioni iconografiche sulla pittura monumentale della Grecia durante il XIII secolo, CorsiRav 31 (1984), б. 197, عıк. 3. $\mathrm{H} i \delta i \alpha$, Tendenze stilistiche della pittura monumentale in Grecia

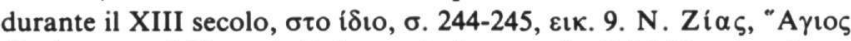

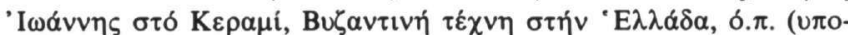

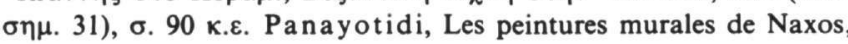

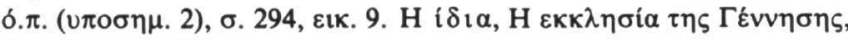

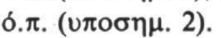

54. G. Millet - A. Frolow, La peinture du moyen âge en Yougoslavie, I, Paris 1954, $\pi$ iv. 85.2-4. R. Hamann-Mac Lean-H. Hallensle ben, Die Monumentalmalerei in Serbien und Makedonien, Giessen

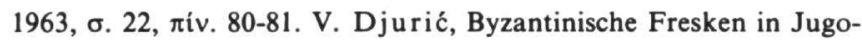
slawien, München 1976, б. 50-51, عıк. 33-34. S. Petković, The Thirteenth Century Frescoes in Moraća Monastery. A Reinterpretation, Actes XVe Congrès International d'études byzantines, Athènes 1976,

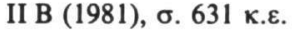

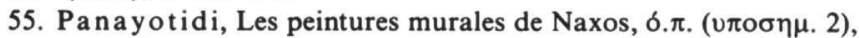

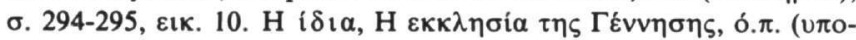
$\sigma \eta \mu .2)$.

56. Hamann-Mac Lean-Hellensleben, ó. $\pi$., б. 23-24, عıк. 100-

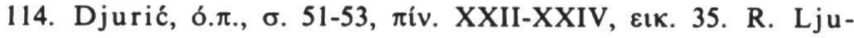
bincović, Die Apostelkirche im Patriarchat von Peć, Beograd $1977^{2}$. V. Djurić-Sima Djirković-V. Korać, Pedjka Patrijaršija, Beograd $1990, \sigma .33$ к.E.

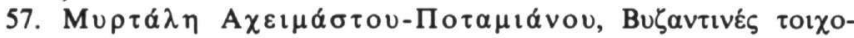

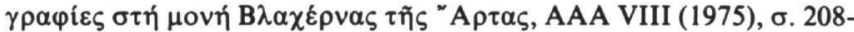
216. H i $\delta ı \alpha$, The Byzantine Wall Paintings of Vlacherna Monastery (Area of Arta), Actes XVe Congrès International d'études byzantines,

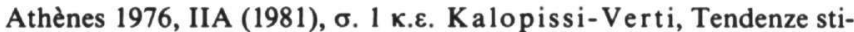

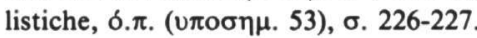

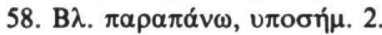

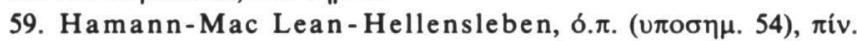

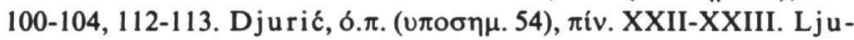

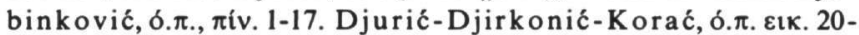
25 .

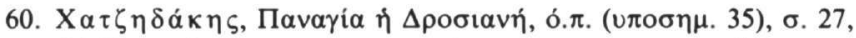

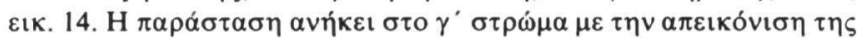

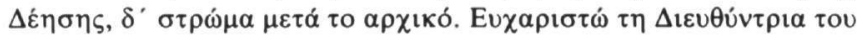

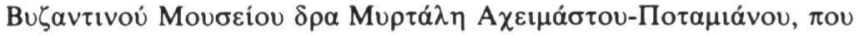

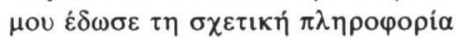

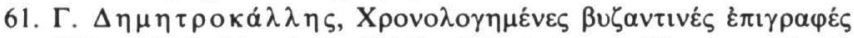

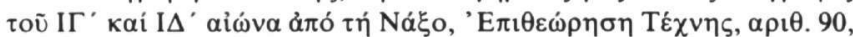

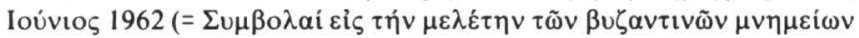

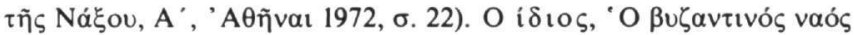

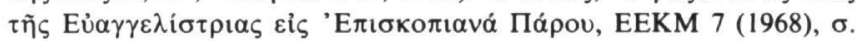

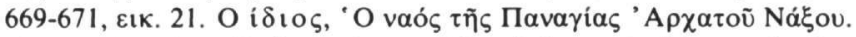

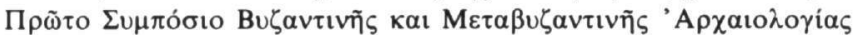

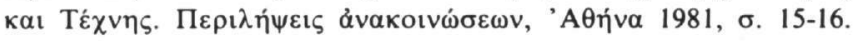

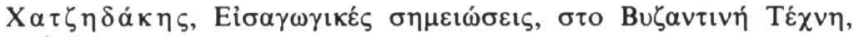

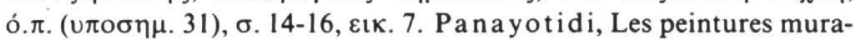

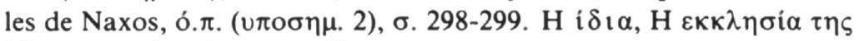

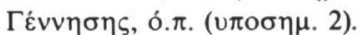

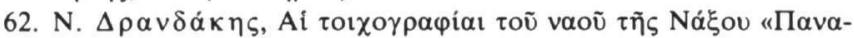

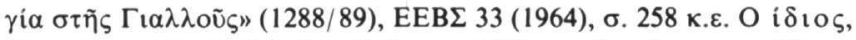

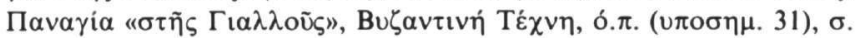

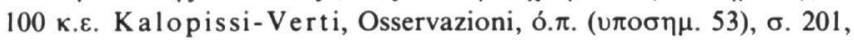
206-207. Panayotidi, Les peintures murales de Naxos, ó. $\pi .$, б. 298-

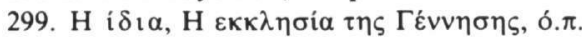

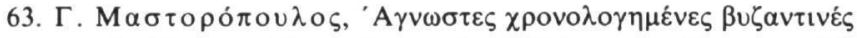

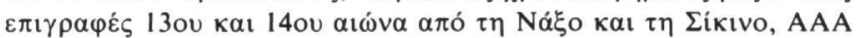

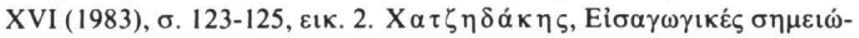

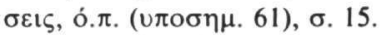

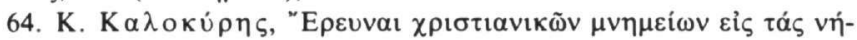

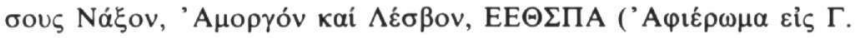

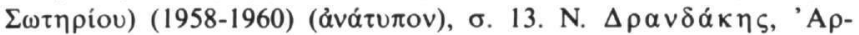

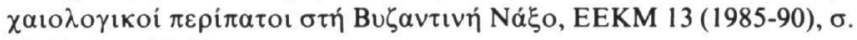
17-18, عเк. 13-16

65. Th. Whittemore, The Mosaics of Haghia Sophia at Istanbul. Fourth Preliminary Report. The Deesis Panel of the South Gallery, Oxford 1952. O. Demus, Die Entstehung des Paläologenstils in der Malerei, Berichte zum XI. Internationalen Byzantinistenkongress,

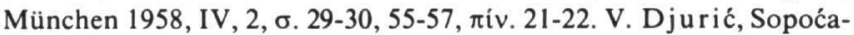
ni, Leipzig 1967. D. Talbot Rice, The Church of Haghia Sophia at Trebizond, Edinburgh 1968. 


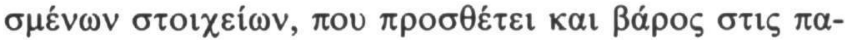

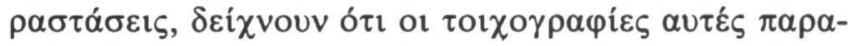

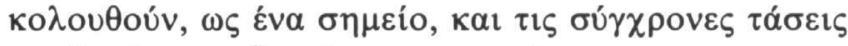

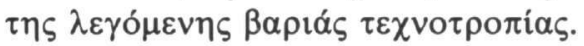

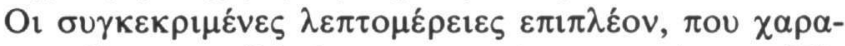

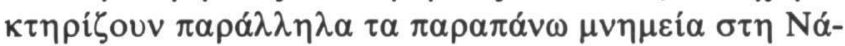

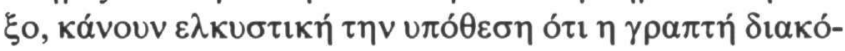

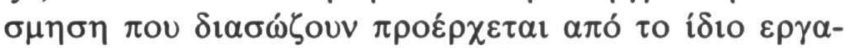

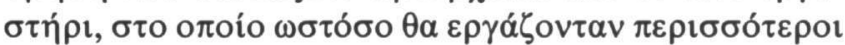

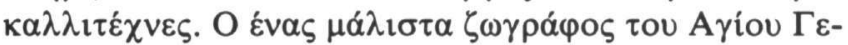

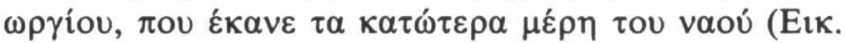

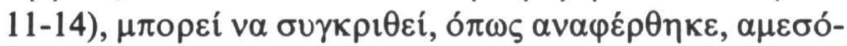

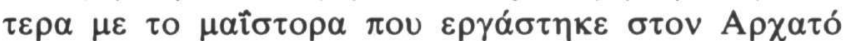

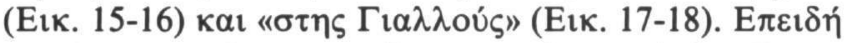

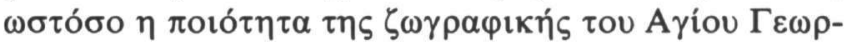

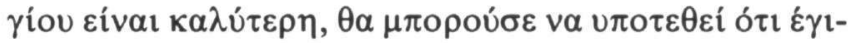

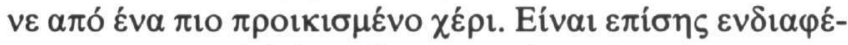

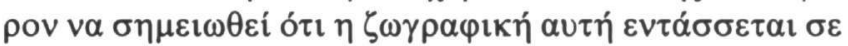

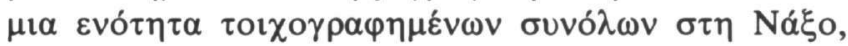

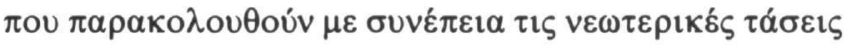

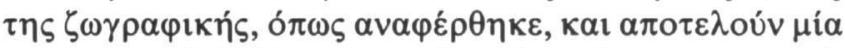

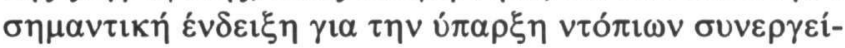
$\omega v$.

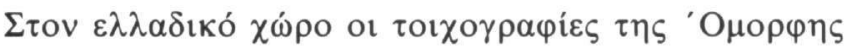

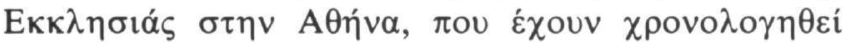

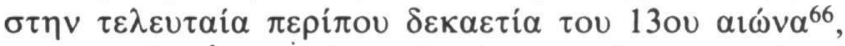

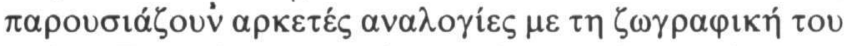

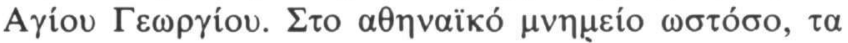

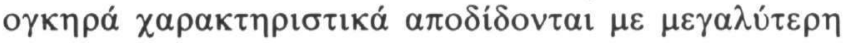

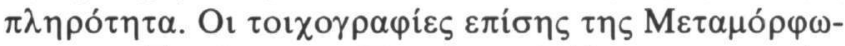

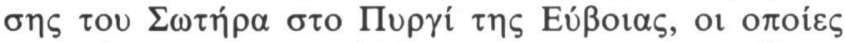

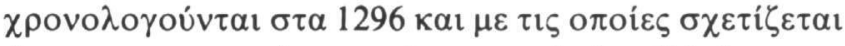

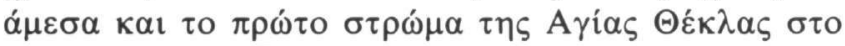

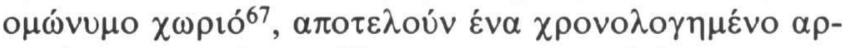

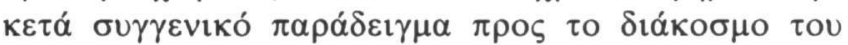

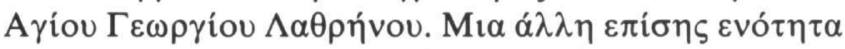

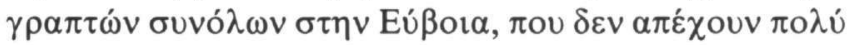

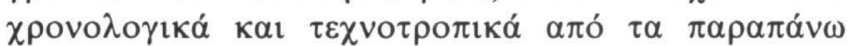

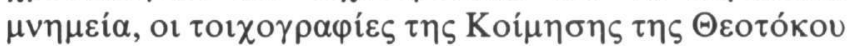

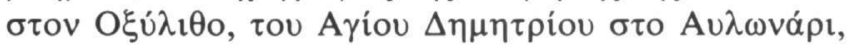

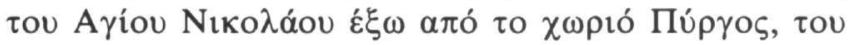

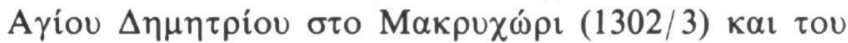

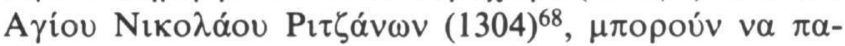
$\rho \alpha \lambda \lambda \eta \lambda \iota \sigma \tau o u ́ v \varepsilon \pi i ́ \sigma \eta \varsigma \mu \varepsilon \tau \eta \zeta \omega \gamma \rho \alpha \varphi ı$

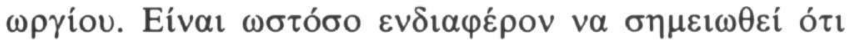

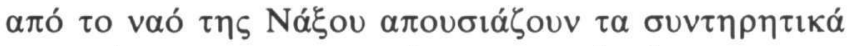

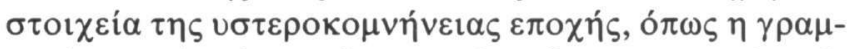

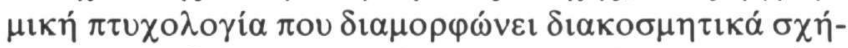

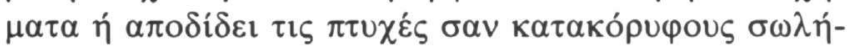

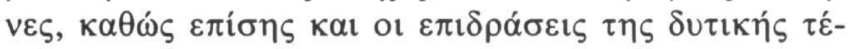
$\chi \vee \eta s$.

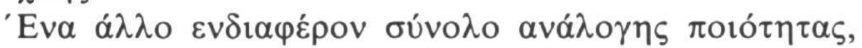

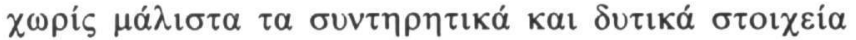

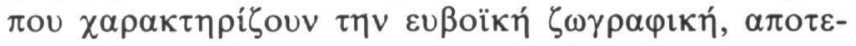

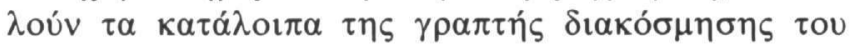

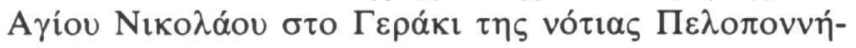

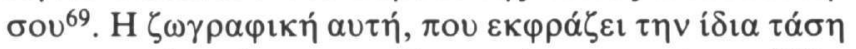

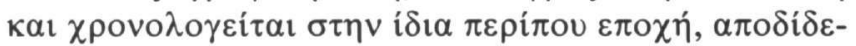

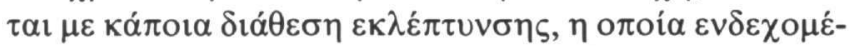

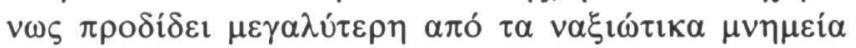

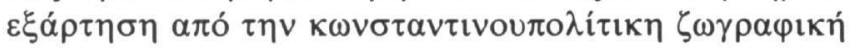

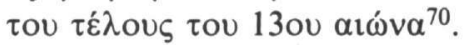

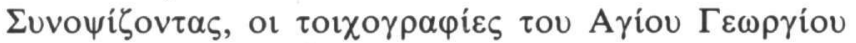

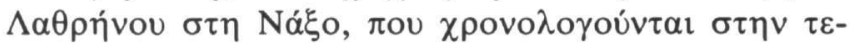

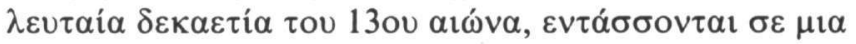

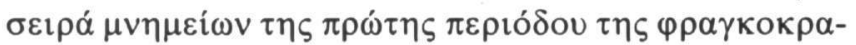

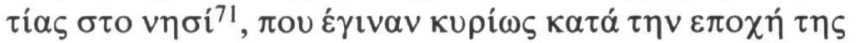

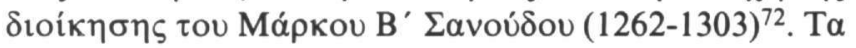

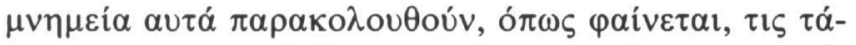

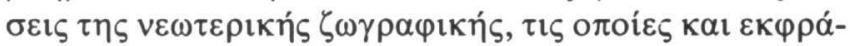

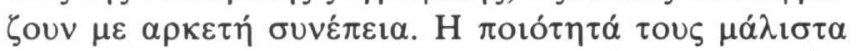

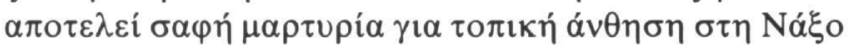

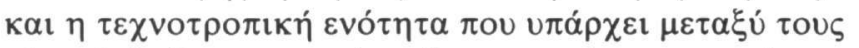

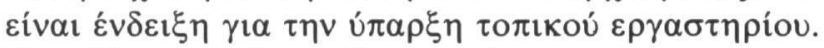

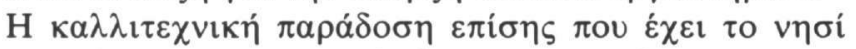

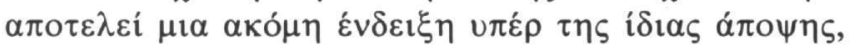

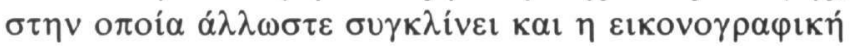

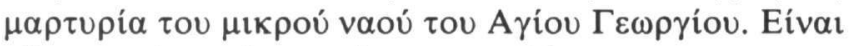

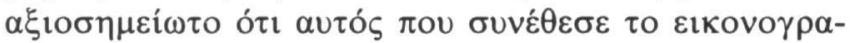

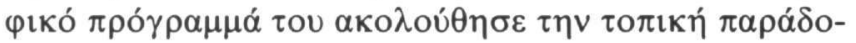

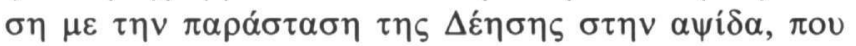

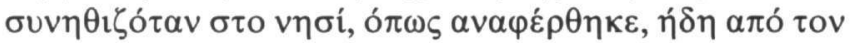

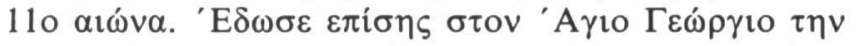

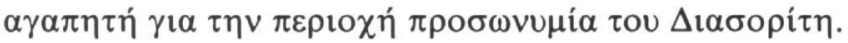

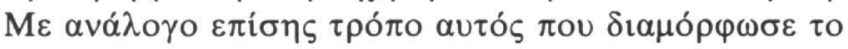

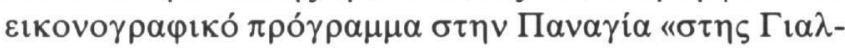

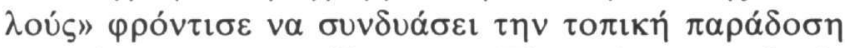

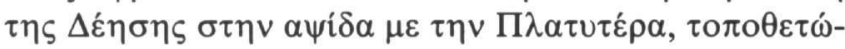

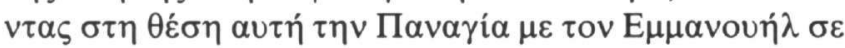

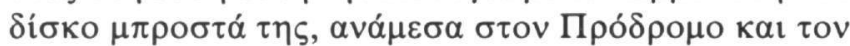
$\alpha \rho \chi \alpha \dot{\gamma} \gamma \varepsilon \bar{\varepsilon} \mathrm{O}$ M $\chi \alpha \eta^{\prime} \lambda^{73}$.

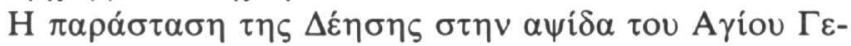

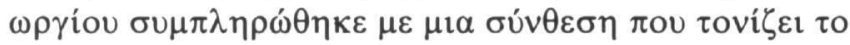

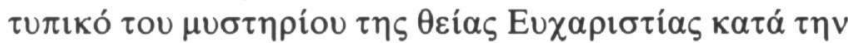

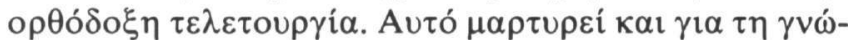

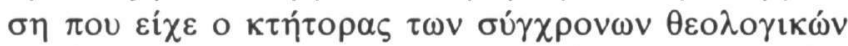

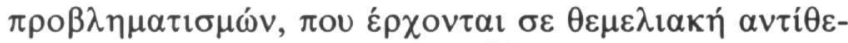

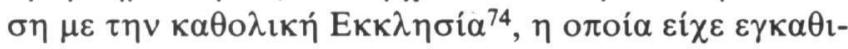

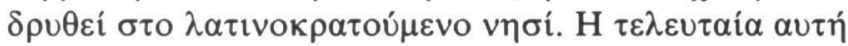

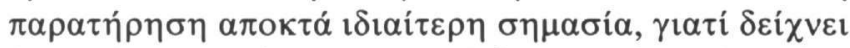

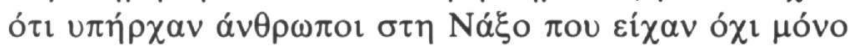

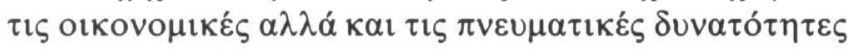

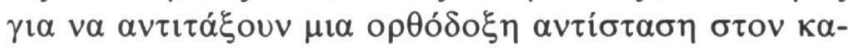

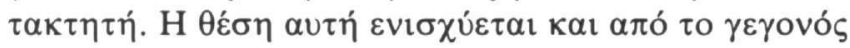




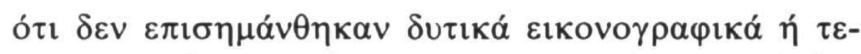

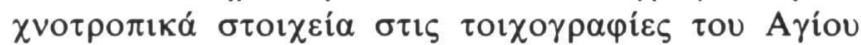

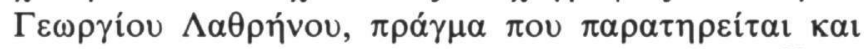

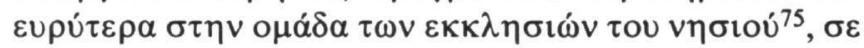
$\alpha v \tau i \theta \varepsilon \sigma \eta \mu \varepsilon \tau \eta \zeta \omega \gamma \rho \alpha \varphi \iota \kappa \eta ́ ~ \sigma \varepsilon \alpha \dot{\lambda} \lambda \varepsilon \varepsilon \varsigma \lambda \alpha \tau \iota v o \kappa \rho \alpha \tau o u ́ \mu \varepsilon-$

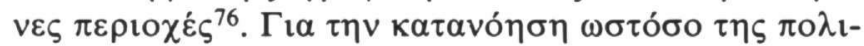

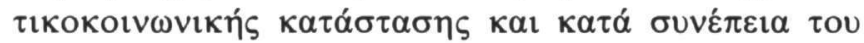

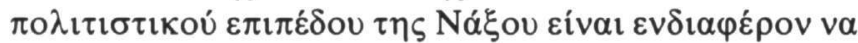

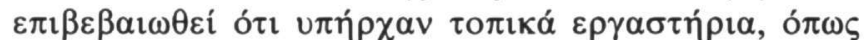

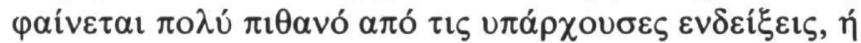

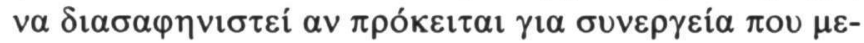

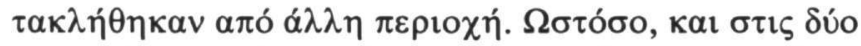

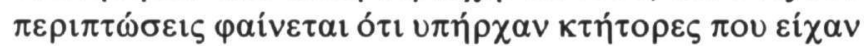

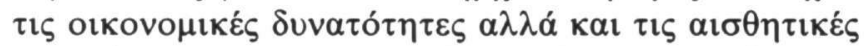

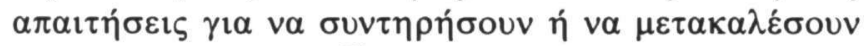
$\alpha v \alpha ́ \lambda o \gamma \alpha \varepsilon \rho \gamma \alpha \sigma \tau \eta \dot{\rho} \rho \alpha^{77}$.

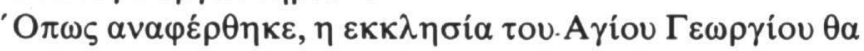

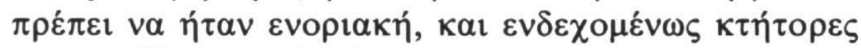

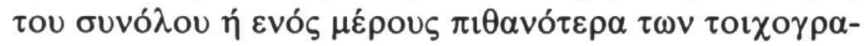

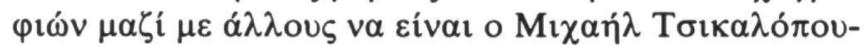

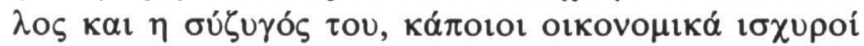

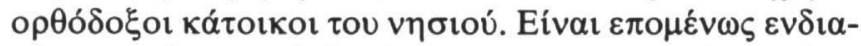

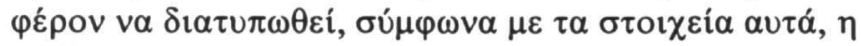

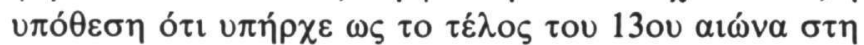

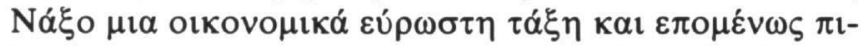

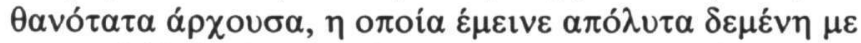

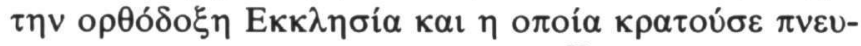

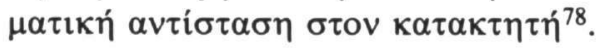

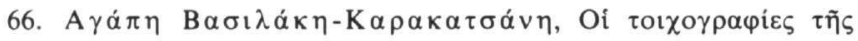

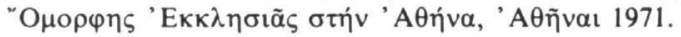

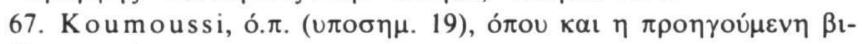
$\beta \lambda$ เоррачі́a.

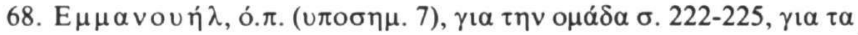

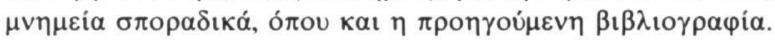

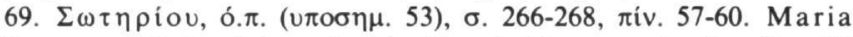
Panayotidi, Les églises de Géraki et de Monemvasie, CorsiRav 22

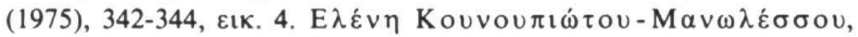

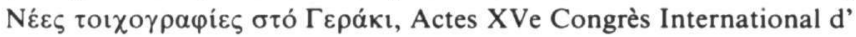
études byzantines, Athènes 1976, II A (1981), б. 323, عıк. 15. N. Mov-

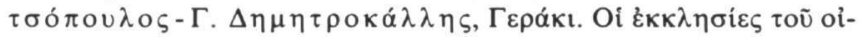

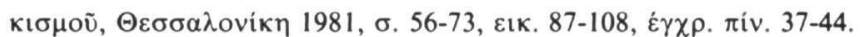

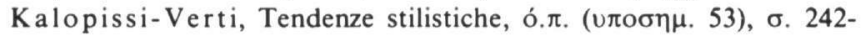
243.

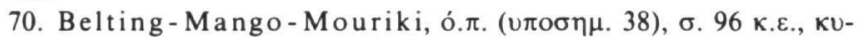

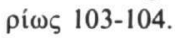

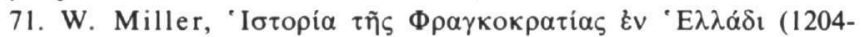

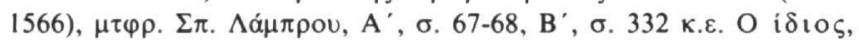

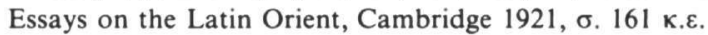

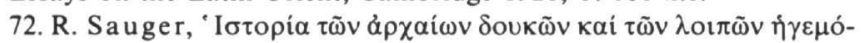

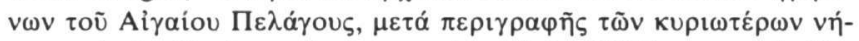

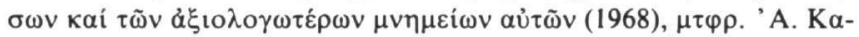

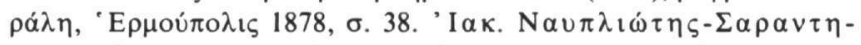

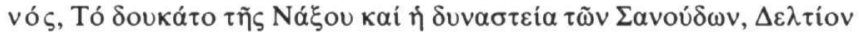

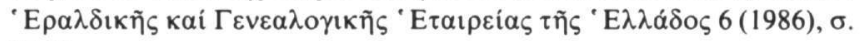
85-90.

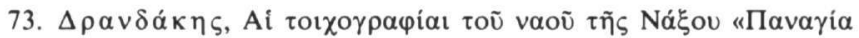

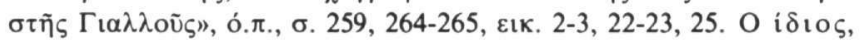

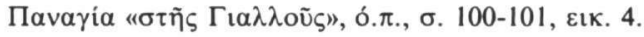

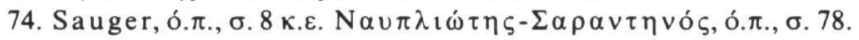
W. Miller, The Latins in the Levant, London 1908, $\sigma .573$.

75. B $\lambda . \pi \alpha \rho \alpha \pi \alpha ́ v \omega, \sigma .150$.

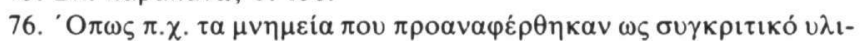

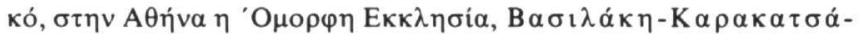

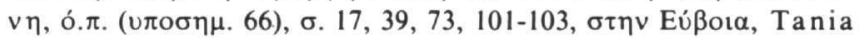
Velmans, Deux églises byzantines du début du XIVe siècle en Eubée,

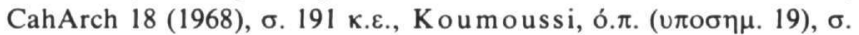

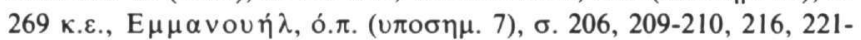
222.

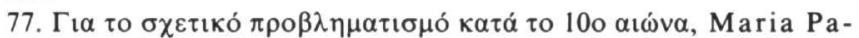
nayotidi, The Character of Monumental Painting in the Tenth Cen-

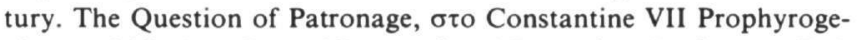
nitus and his Age, Second International Byzantine Conference, Del-

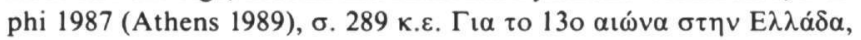
Sophia Kalopissi-Verti, Dedicatory Inscriptions and Donor Portraits in Thirteenth Century Churches of Greece, Veröffentlichungen der Kommission für die TIB, Bd 5, Wien 1992. Гєvıкá $\beta \lambda$. Gordana Babić, Peintures murales byzantines et de tradition byzantine (10811453), Possibilités et limites des analyses sociologiques, XVIIIe Congrès International des études byzantines, Moscou 1991, Rapports pléniers, $\sigma .348$ к.ع.

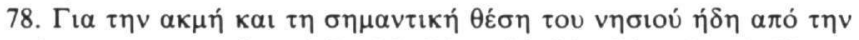

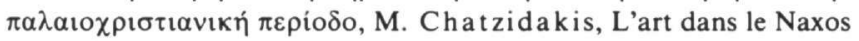
byzantin et le contexte historique, XVe Congrès International des sciences historiques, Bucarest 1980, Rapports III, $\sigma .13-15$. O $\mathrm{i} \delta 10 \varsigma$,

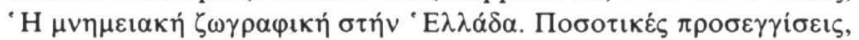
ПАА $56, \tau \chi .20$ (1981), $\sigma .382-383.0$ i $\delta\llcorner\circ$, Les aspects de la peinture monumentale byzantine en Grèce, Extrait du GLAS CCCXXXVIII de l'Académie serbe des sciences et des arts, Classe des sciences historiques 3, Beograd 1983, б. 5-6. E. Malamut, Les îles de l'empire byzantin, VIIIe-XIIe siècles, Paris 1988, б. 216-218, 267-269, 319 каı $\sigma \pi \circ \rho \alpha \delta$ เќ. 


\section{Maria Panayotidi}

\section{LES PEINTURES MURALES \\ DE SAINT-GEORGES DE LATHRINO A NAXOS}

$\mathrm{L}$

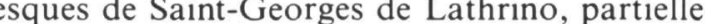
ment conservées, en effet se trouvent dans la partie sud, consacrée à Saint Georges, d'une petite église double (Fig. 1). La partie nord est dédiée à Saint Nicolas.

Dans le quart de sphère de l'abside de cette chapelle est figurée la Deésis (Fig. 2). Dans l'hémicylindre le Melismos (Fig. 5) est représenté entre deux anges-diacres (Figs. 6-7) et quatre évêques officiant: saint Athanase, saint Jean Chrysostome (Fig. 8), saint Basile (Fig. 9) et saint Grégoire le Théologien. A gauche de saint Athanase, une inscription votive est conservée, qui mentionne Michel Tsykalopoulos et son épouse.

Sur le front de l'abside l'Ancien de Jours (Fig. 10), assez détérioré, est représenté, en buste, entouré des quatre symboles des Évangélistes avec, de part et d'autre, l'ange et la Vierge de l'Annonciation. En dessous de ces derniers se trouvent les parents de la Vierge Joachim et Anne. Puis, sous Joachim, le diacre Étienne avec, en pendant, à droite, un évêque représenté de face.

Dans le tympan de l'arc aveugle, sur le mur nord du béma, figurent, à droite, saint Nicolas (Fig. 11) et, à gauche, une sainte femme (Fig. 12), tandis que la représentation au milieu, celle de la Vierge, a été détruite. Dans le tympan du deuxième arc aveugle sont représentés saint Georges Diassoritis à droite et un jeune apôtre à gauche (Figs. 13-14), Philippe ou Thomas. Dans le tympan ouest sont conservées quelques traces d'un saint militaire.

Du point de vue iconographique, les représentations du décor peint de la chapelle Saint-Georges présentent un intérêt spécial, car leur nombre permet une lecture et une interprétation sémantique.

Ainsi, le Logos éternel, représenté sur le front de l'abside, dont l'Incarnation s'est réalisée par l'Annonciation qui est confirmée par Joachim et Anne et que garantissent les deux principaux témoins de l'œuvre du Salut, la Vierge et saint Jean Prodrome, gouverne l'univers et, représenté dans l'abside en tant que Pantocrator Philanthropos, protège l'humanité, la ville et les fidèles. Il reçoit son propre sacrifice non-sanglant qui «nourrit les élus»; ce sacrifice est figuré dans l'hémicylindre.

Il est intéressant de constater que l'ensemble du programme iconographique de l'abside a été adapté de façon à exprimer avec clarté et connaissance dogmatique les nuances qui, depuis le XIIe siècle, ont dominé dans l'iconographie byzantine. De plus, est représenté le dogme de l'identité de Celui qui est offert avec Celui qui reçoit le sacrifice eucharistique, ainsi que le rite du mystère de l'Eucharistie, selon l'église orthodoxe.

Du point de vue stylistique ces fresques suivent les tendances modernes de l'art métropolitain et elles datent de la dernière décennie du XIIIe siècle. Elles présentent en effet des affinités intéressantes avec des monuments de cette période à Naxos, la Vierge à Archatos, 1285 (Figs. 15-16) et la Vierge "stis Giallous", 1288/89 (Figs. 17-18). De plus, elles peuvent être comparées avec des monuments datant à peu près de cette période, ailleurs dans l'Empire, en Attique, en Eubée, dans le Péloponnèse. Une série de peintures de Naxos, comparables à l'art de Saint-Georges et datant des années 1260-1280, apportent une preuve importante de la situation florissante de l'île lors de la première période de l'occupation latine, situation qui permettait très probablement l'existence d'ateliers locaux de peinture.

L'église Saint-Georges devait être paroissiale et les donateurs probables de l'ensemble ou d'une partie de son décor pourraient être Michel Tsykolopoulos et son épouse, sans doute un couple assez riche qui habitait dans l'île. Ces éléments permettent de supposer qu'il y existait jusqu'à la fin du XIIIe siècle une classe sociale assez riche qui continuait d'être étroitement liée avec l'église orthodoxe et qui opposait une resistance intellectuelle non négligeable aux conquérants. 